ARTICLE

https://doi.org/10.1038/s41467-019-09678-w

\title{
Spy\&Go purification of SpyTag-proteins using pseudo-SpyCatcher to access an oligomerization toolbox
}

Irsyad N.A. Khairil Anuar (10 ${ }^{1}$, Anusuya Banerjee ${ }^{1}$, Anthony H. Keeble (iD ${ }^{1}$, Alberto Carella ${ }^{1}$, Georgi I. Nikov (i) ${ }^{1} \&$ Mark Howarth (1) 1

Peptide tags are a key resource, introducing minimal change while enabling a consistent process to purify diverse proteins. However, peptide tags often provide minimal benefit postpurification. We previously designed SpyTag, forming an irreversible bond with its protein partner SpyCatcher. SpyTag provides an easy route to anchor, bridge or multimerize proteins. Here we establish Spy\&Go, enabling protein purification using SpyTag. Through rational engineering we generated SpyDock, which captures SpyTag-fusions and allows efficient elution. Spy\&Go enabled sensitive purification of SpyTag-fusions from Escherichia coli, giving superior purity than His-tag/nickel-nitrilotriacetic acid. Spy\&Go allowed purification of mammalian-expressed, $\mathrm{N}$-terminal, C-terminal or internal SpyTag. As an oligomerization toolbox, we established a panel of SpyCatcher-linked coiled coils, so SpyTag-fusions can be dimerized, trimerized, tetramerized, pentamerized, hexamerized or heptamerized. Assembling oligomers for Death Receptor 5 stimulation, we probed multivalency effects on cancer cell death. Spy\&Go, combined with simple oligomerization, should have broad application for exploring multivalency in signaling.

\footnotetext{
${ }^{1}$ Department of Biochemistry, University of Oxford, South Parks Road, Oxford OX1 3QU, UK. Correspondence and requests for materials should be addressed to M.H. (email: mark.howarth@bioch.ox.ac.uk)
} 
A ffinity chromatography is a central enabling technology for research and for producing therapeutics, vaccines, and diagnostics ${ }^{1,2}$. However, a persistent problem with affinity tags is paradoxically the tags themselves, since the tags often serve no purpose post-purification. Tags can inhibit crystallization ${ }^{3}$, interfere with protein interactions ${ }^{4}$, and produce an unhelpful immune response in vivo ${ }^{5}$. Tags may be removed by proteolysis but this extra step is time-consuming, often inefficient and reduces overall yield ${ }^{6,7}$.

There are already a multitude of affinity tags ${ }^{1,8-11}$. However, each tag presents its own limitations. The most widely used, the His-tag, is not without faults. There are many examples of His-tagging disrupting protein solubility ${ }^{12}$, structure ${ }^{13,14}$, and function ${ }^{15,16}$. His-tag purification faces particular challenges from leakage of metal ions into downstream assays ${ }^{17,18}$ and substantial immunogenicity ${ }^{5}$. The four-amino acid C-tag is less immunogenic but is only functional at the C-terminus ${ }^{8}$. Apart from purification, it would be desirable to use peptide tags for assembly or immobilization, but the low stability of peptide interactions is frequently limiting ${ }^{19,20}$.

We previously developed a peptide-protein pair, SpyTag and SpyCatcher, that spontaneously forms a covalently-linked complex $^{21,22}$ (Fig. 1). We continued the progress by increasing the rate of reaction via the evolved SpyTag002 and SpyCatcher002 versions ${ }^{23}$. SpyTag technology has enabled diverse applications including Plug-and-Display vaccine assembly ${ }^{24-26}$, multivalent activation of signaling 27 , modular antibody decoration $^{28}$, and living or catalytic biomaterials ${ }^{29-32}$. Up until now, Spy proteins were nearly always purified via a His-tag, which required further tag cleavage for immunological applications ${ }^{24}$. Here, we report the development of an affinity chromatography technique employing SpyTag as a purification tag, by step-wise engineering of the SpyCatcher protein partner (Fig. 1). In addition, to extend the modular expansion of protein function, we establish a toolbox for oligomerization of proteins of interest using SpyTag-mediated covalent reaction. These oligomers shed light on the nature of multivalent signaling of DR5 to induce cancer cell killing.

\section{Results}

Establishment of the Spy\&Go purification system. As a first step to establish Spy\&Go purification, the formation of an isopeptide bond between SpyCatcher and SpyTag must be abrogated, to make possible the elution of SpyTag-fusions. To generate a nonreactive "pseudo-SpyCatcher", the activating glutamic acid residue in the CnaB2 triad (E77, Fig. 1) was mutated to aspartic acid to retain the charge, or to alanine, glycine, asparagine, glutamine, serine, threonine, or valine to remove any possibility of proton donation/acceptance ${ }^{33}$. We mixed SpyTag-MBP and the E77X variants at $25^{\circ} \mathrm{C}$ for $24 \mathrm{~h}$. E77D still showed a small amount of reaction with SpyTag-MBP, but no trace of reaction was seen with any other mutation (Fig. 2a).

To advance Spy\&Go purification further, we hypothesized that the rate of association between SpyTag and the SpyCatcher moiety could be limiting. We have previously generated SpyCatcher002 through phage display evolution for enhanced interaction with SpyTag ${ }^{23}$. Here we additionally increased the negative surface charge on SpyCatcher and reduced the flexibility in one of the loops through proline substitution, generating SpyCatcher2.1. When purified SpyTag-MBP was incubated with the different E77X variants, SpyCatcher002 led to more efficient capture and elution than SpyCatcher, while SpyCatcher2.1 was more effective still (Fig. 2b). Comparing alternative E77 mutations for SpyCatcher2.1, E77A led to recovery of the highest amount of SpyTag-MBP (Fig. 2b). Hence, this mutant was taken forward for subsequent development.

We aimed to attach SpyCatcher2.1 E77A site-specifically to sepharose beads, for maximum accessibility to SpyTag-fusions. A unique cysteine was introduced in SpyCatcher2.1 E77A at three positions. Cysteine introduction sites were selected for efficient coupling to iodoacetyl-activated (SulfoLink) beads as well as for minimal disruption to SpyTag/SpyCatcher2.1 binding, by having the cysteine substitutions distal from the $\mathrm{CnaB} 2$ reactive triad (Fig. 2c). Three mutations were examined: N-terminal cysteine (N-term Cys) preceding the coding sequence of SpyCatcher2.1, S49C and S55C 34,35 (Fig. 2c). After immobilizing SpyCatcher2.1
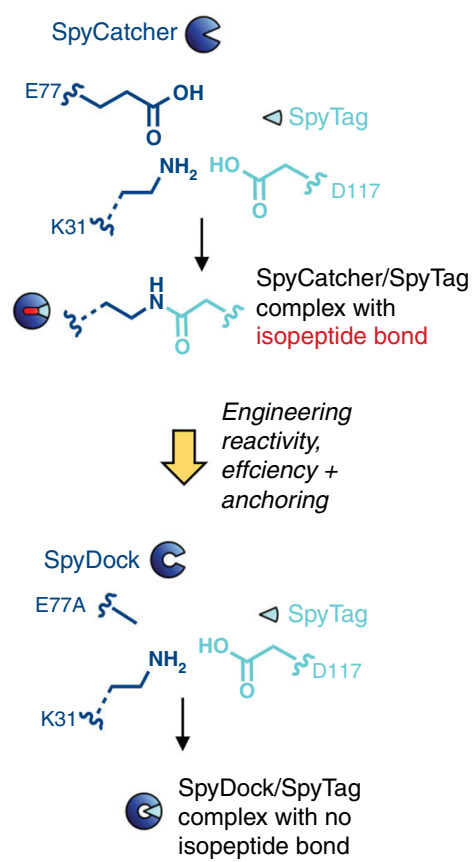

1) Spy\&Go purification

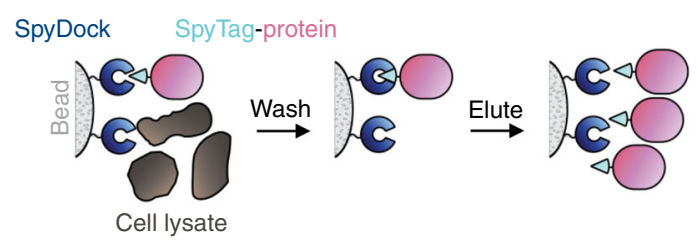

2) Assembly using SpyCatcher platforms

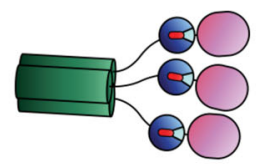

$n=2,3,4,5,6,7$

Oligomerization toolbox

Spy-nanostructures

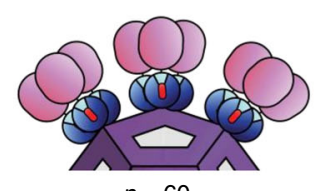

$n=60$

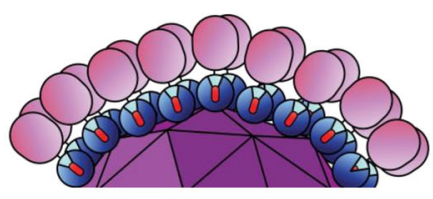

$n=180$

Fig. 1 Overview of Spy\&Go. SpyTag/SpyCatcher interact irreversibly by spontaneous isopeptide bond formation, promoted by E77. SpyTag purification requires the generation of reversible interaction with SpyDock in 3 steps: blocking reaction, enhancing efficiency of SpyTag binding and precise immobilization on resin. Spy\&Go then enables purification of SpyTag-fusions, setting the stage for modular oligomerization or multimerization 
a

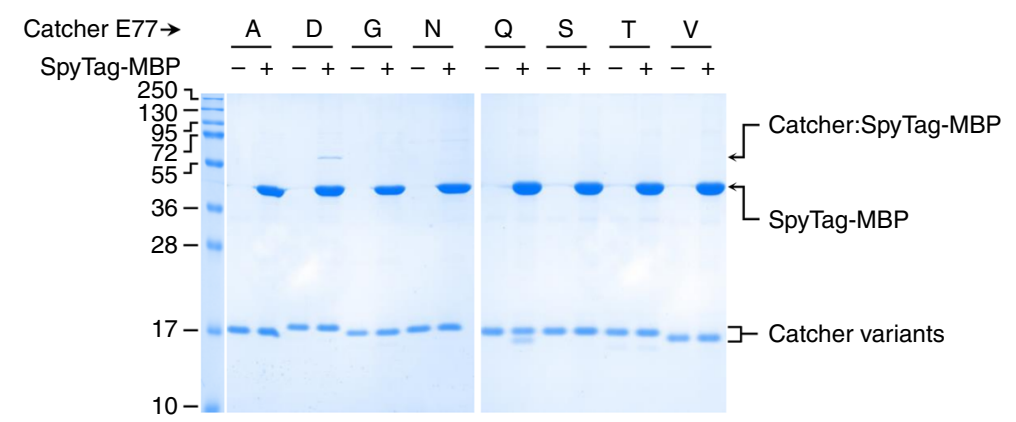

b

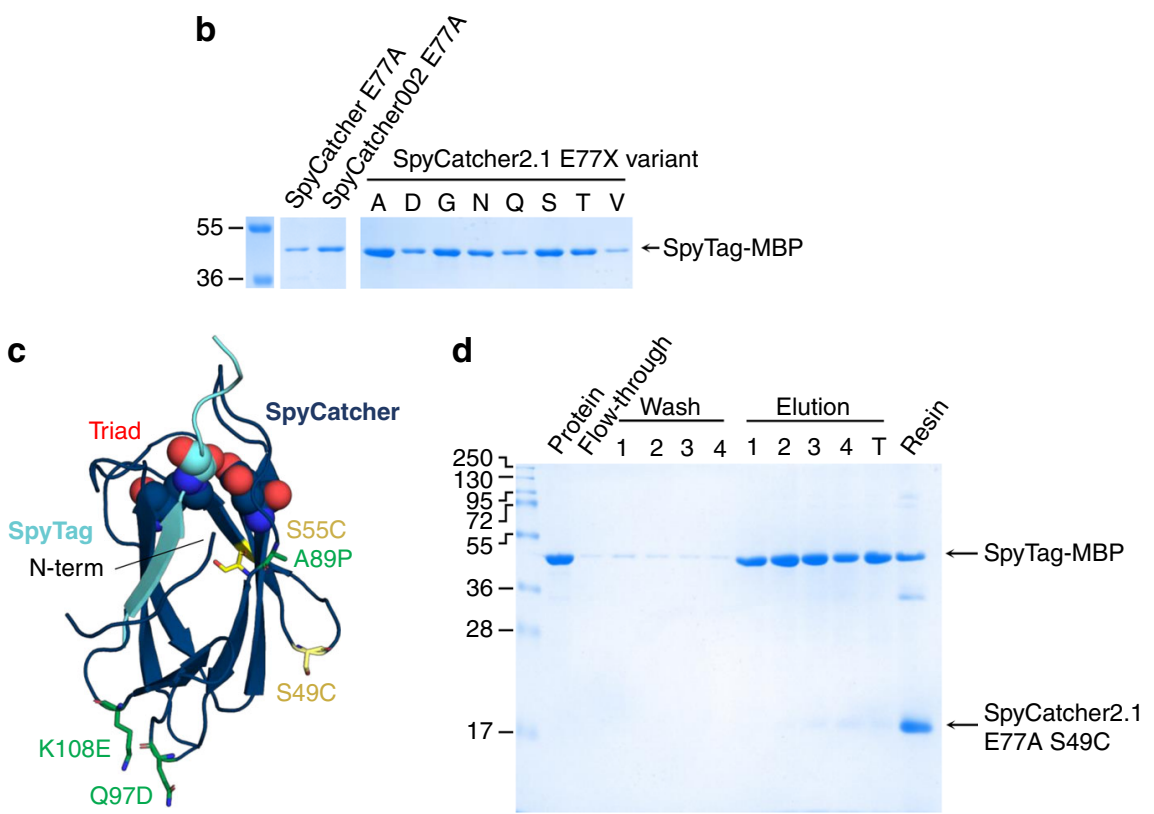

Fig. 2 Design of SpyDock. a All small residues except D blocked SpyCatcher reaction. E77 was mutated to the indicated residue and incubated with SpyTag-MBP for $24 \mathrm{~h}$, before boiling in SDS and analysis by SDS-PAGE with Coomassie staining. b Additional mutations in SpyCatcher enhanced Spy\&Go purification. The original SpyCatcher, the evolved SpyCatcher002 or SpyCatcher2.1 bearing the E77A mutation were compared for capture and elution of SpyTag-MBP (SDS-PAGE with Coomassie staining). Further E77X mutations were similarly explored on SpyCatcher2.1. c Positions of mutations screened for SpyDock acceleration, based on Protein Data Bank 4MLI; CnaB2 triad represented in spheres, anchoring sites in yellow, and SpyCatcher2.1 accelerating mutations in green. d S49C resin anchoring allowed efficient SpyDock purification. SpyCatcher2.1 E77A S49C was coupled to SulfoLink resin and tested for SpyTag-MBP capture and release (SDS-PAGE with Coomassie staining)

E77A with each cysteine mutation, purified SpyTag-MBP was mixed with the resin, washed, and eluted. All Cys mutants showed similar SpyTag-MBP retention and minimal leak-through during washes, but S49C had the least SpyTag-MBP left on the resin after 4 elutions (Fig. 2d and Supplementary Fig. 1). Therefore, the finalized protein for Spy\&Go purification was SpyCatcher2.1 S49C E77A, hereafter termed SpyDock (amino acid sequence in Supplementary Fig. 2). SpyDock can be coupled to SulfoLink resin to achieve $14.2 \mathrm{mg}$ of SpyDock protein per $\mathrm{mL}$ of resin (Supplementary Fig. 3).

To test how well SpyDock bound to SpyTagged proteins, we used isothermal titration calorimetry (ITC) to measure the dissociation constant $\left(K_{\mathrm{d}}\right)$ for SpyDock's interaction with SpyTag-MBP (Fig. 3a) or SpyTag002-MBP (Fig. 3b). Both proteins bound with 1:1 stoichiometry. SpyTag002-MBP $\left(K_{\mathrm{d}}=0.073 \mu \mathrm{M}\right)$ bound $\sim 10$-fold tighter than SpyTag-MBP $\left(K_{\mathrm{d}}=0.75 \mu \mathrm{M}\right)$, consistent with the improved properties of the second-generation Tag/Catcher technology 23 .

Purification of model proteins. With the Spy\&Go resin finalized, we sought to evaluate the capability of the system for purifying proteins from cellular material. Affinity purification becomes easier when proteins are highly over-expressed, so we challenged the system by doping a low amount of purified SpyTag-MBP into clarified E. coli lysate at $0.36 \mathrm{mg}$ protein per $\mathrm{g}$ of wet cell weight. As a comparison, we typically obtain $\sim 5 \mathrm{mg}$ of purified recombinant protein per $g$ of $E$. coli wet cell weight ${ }^{26}$. A series of optimizations established that $2.5 \mathrm{M}$ imidazole at neutral $\mathrm{pH}$ was efficient at eluting SpyTag from SpyDock, with lower imidazole concentrations used in the wash buffer ${ }^{36}$. Imidazole is an inexpensive and highly soluble reagent, already present in most biochemistry laboratories. As a bench mark for Spy\&Go purification, the SpyTag protein also had a $\mathrm{His}_{6}$-tag, so that the same protein and lysate could be compared for the common approach of $\mathrm{Ni}$ NTA purification. The same amount of His-tagged SpyTag-MBP in clarified E. coli lysate was mixed with Ni-NTA resin at the same volume. Spy\&Go-based purification enabled purification of SpyTag-MBP with higher purity $(98.9 \pm 0.5 \%)$ than via Ni-NTA purification $(66.4 \pm 1.9 \%)$, as seen in the pooled elution fractions measured by gel densitometry (Fig. $4 \mathrm{a}, \mathrm{b}$ ). The ability of the resin to bind and sequester a low concentration of input protein also indicates the sensitivity of Spy\&Go as a purification platform.

SpyTag is the most widely used partner of SpyCatcher in the literature $^{22,37,38}$, so our purification approaches focused on this 
a
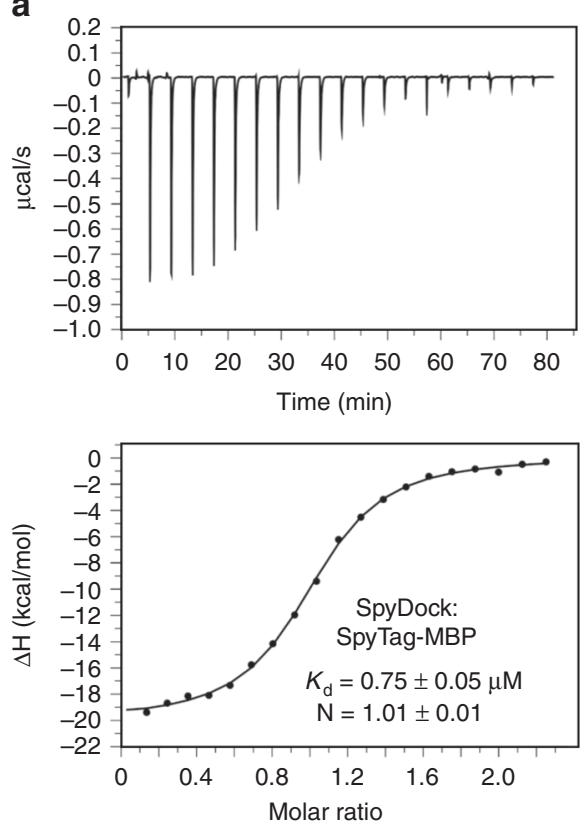

b
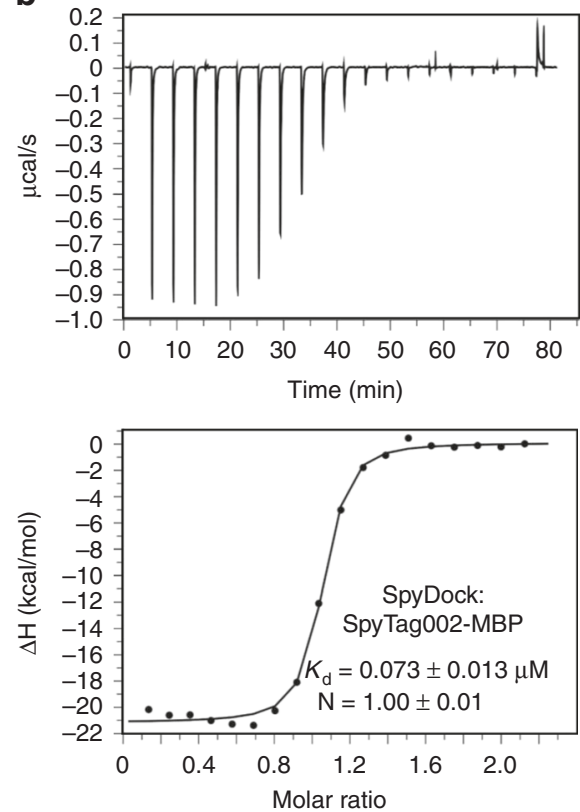

Fig. 3 Affinity of SpyDock for its targets. ITC binding isotherms for SpyDock binding at $25^{\circ} \mathrm{C}$ to a SpyTag-MBP or b SpyTag002-MBP. Error bars represent the uncertainty in fit to the binding curve using a 1:1 binding model

tag version. However, we also validated that Spy\&Go was efficient for purification of a SpyTag002-fusion ${ }^{23}$ (Supplementary Fig. 4A).

Additionally, Spy\&Go resin was still capable of purifying SpyTag-MBP from bacterial lysate after storage of resin in $20 \%$ (v/v) ethanol for 12 weeks. Therefore Spy\&Go resin showed good stability, as long as microbial growth was inhibited (Supplementary Fig. 4B).

Spy\&Go allowed purification with SpyTag at different sites. Some affinity tags can only be placed at either the $\mathrm{N}$ - or Cterminus, thus restricting experimental flexibility, especially if a functional site of the protein of interest is close to a terminus ${ }^{1,8,39}$. To test capture of SpyTag inserted in the loop of a protein, we generated a single-chain dimer of the restriction enzyme PvuII. scPvuII-SpyTag was purified efficiently from soluble $E$. coli expression using Spy\&Go (Fig. 4c). To test capture of SpyTag at the C-terminus of a protein, we expressed a nanobody to Death Receptor 5 (DR5) (aDR5-SpyTag) in the cytosol of E. coli and showed efficient purification using Spy\&Go (Fig. 4d). A single round of purification is not expected to achieve $100 \%$ purity and proteins may be subsequently polished using standard methods such as size-exclusion chromatography or ion-exchange chromatography, as may assist subsequent applications.

To test purification of a different class of protein, the enhanced green fluorescent protein mClover3 was genetically fused with SpyTag at its $\mathrm{N}$-terminus and expressed solubly in E. coli. After purification and dialysis, the fluorescence of mClover3 was comparable to the same protein purified via its His-tag using Ni-NTA (Supplementary Fig. 5), supporting that Spy\&Go purification maintained the functionality of purified proteins. From lysate purifications, the resin capacity ranged from $4-13 \mathrm{mg}$ of protein per $\mathrm{mL}$ of resin, depending on the location of the SpyTag and protein used.

We established effective regeneration of Spy\&Go resin via stripping using $4 \mathrm{M}$ imidazole, guanidinium hydrochloride, and $\mathrm{NaOH}$ (Supplementary Fig. 6A). Following regeneration of the resin, the smaller protein aDR5-SpyTag was purified by Spy\&Go, while SpyTag-MBP (previously purified using the same resin batch) was not detected (Supplementary Fig. 6B). Purification of aDR5-SpyTag using new resin or regenerated resin gave similar results (Supplementary Fig. 6B).

Spy\&Go allowed purification from mammalian expression. Some affinity tags do not work well in particular cell expression systems, requiring extra materials or steps ${ }^{40}$. Transient mammalian expression is becoming a dominant route for the production of many therapeutic and research proteins because of the rapid pipeline, high degree of folding quality control, and the native post-translational modifications (notably $\mathrm{N}$-linked glycosylation $)^{41}$. Epithelial cell adhesion molecule (EpCAM) is a widely used marker for capture of circulating tumor cells and its adhesive interactions may affect metastasis ${ }^{42,43}$. We cloned the soluble extracellular region of EpCAM with SpyTag and His-tag at the C-terminus and expressed this glycoprotein through transient transfection in HEK293T cells. After expression, the same volume of supernatant from the cell culture was incubated with Spy\&Go resin or Ni-NTA resin. EpCAM-SpyTag was efficiently purified using Spy\&Go, as with Ni-NTA (Fig. 5a, b). The heterogeneous gel mobility of EpCAM-SpyTag is expected because of various glycoforms being secreted.

We previously expressed constructs with a His-tag, to allow bench-marking of our purification, but we also purified Cysteinerich Protective Antigen (CyRPA) with a SpyTag but no His-tag. CyRPA from Plasmodium falciparum is a promising blood-stage antigen for malaria vaccination ${ }^{44}$. CyRPA-SpyTag was transiently expressed in Expi293HEK cells and efficiently purified by Spy\&Go (Fig. 5c). Overall, we have shown that Spy\&Go is a viable platform for the purification of proteins with SpyTag at the $\mathrm{N}$-terminus, C-terminus or an internal site from either bacterial or mammalian expression systems.

Oligomeric assembly of SpyTag-fusions. An important feature of using SpyTag as the peptide tag for a protein of interest is that SpyTag can then enable a range of subsequent bioconjugation reactions. For example, SpyTag allows irreversible immobilization 
a

\section{Spy\&Go from bacterial lysate (N-terminal tag)}

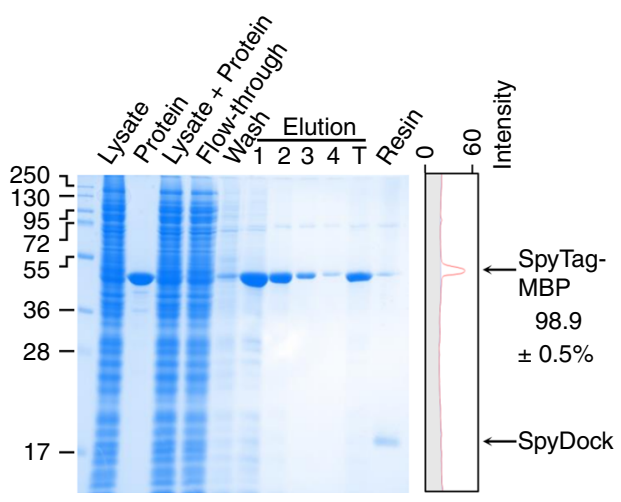

C Spy\&Go from bacterial lysate (internal tag)

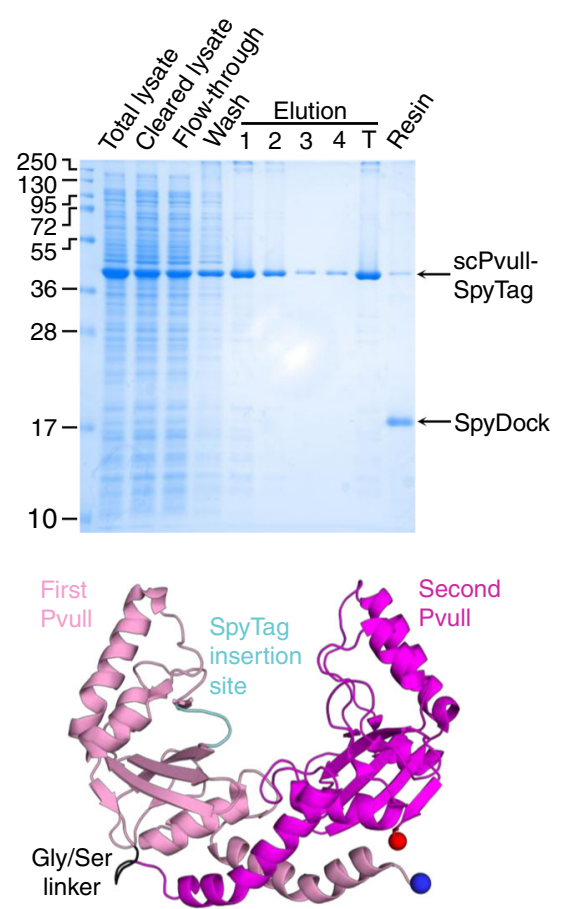

b

Ni-NTA from bacterial lysate

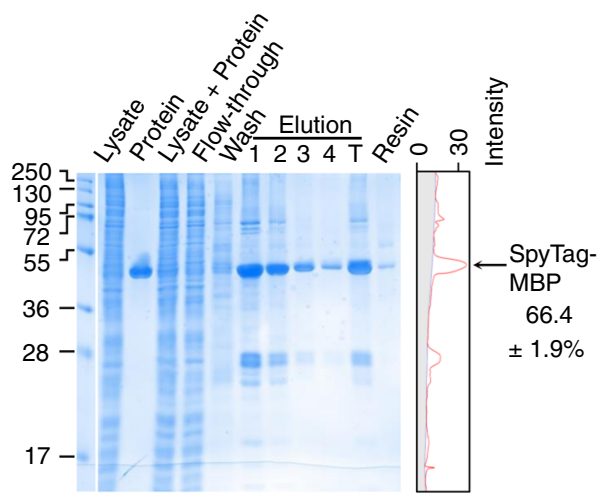

d Spy\&Go from bacterial lysate (C-terminal tag)

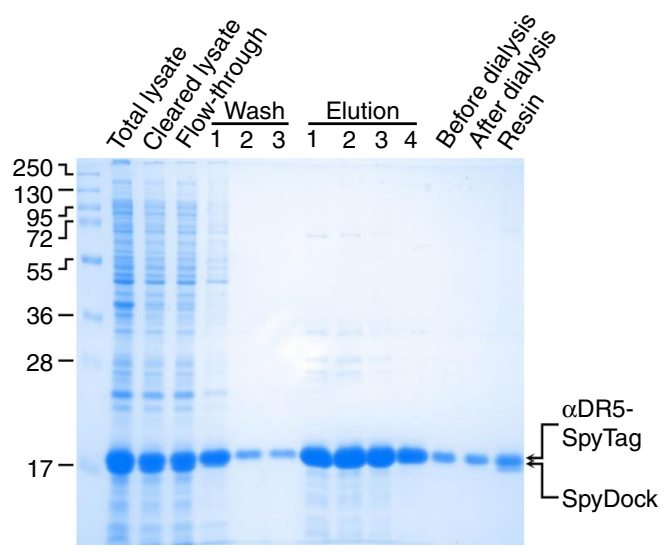

Fig. 4 Spy\&Go from bacterial expression. a SpyTag-MBP was purified from E. coli clarified lysate by Spy\&Go. Protein: input SpyTag-MBP protein. T: total pooled elutions. Purity of T was determined by densitometry (right); gray represents background lane intensity (mean $\pm 1 \mathrm{~s} . \mathrm{d} ., n=3$ ). b Ni-NTA purification of SpyTag-MBP from the same lysate via its His-tag. c Spy\&Go purification of scPvull-SpyTag (SpyTag at an internal loop, shown schematically) from bacterial lysate. $\mathbf{d}$ Spy\&Go purification of the nanobody $\alpha$ DR5-SpyTag (C-terminal fusion) from bacterial lysate. All fractions were analyzed by SDS-PAGE with Coomassie staining

on surfaces or hydrogels $29,30,45$, or high-level multimerization on virus-like particles to accelerate vaccine generation ${ }^{24,26,37}$. To extend the application of SpyTag-fusions, here we also explored the ability for rapid assembly of dimers, trimers, tetramers etc. of the protein of interest. We aimed to prepare a panel of parallel coiled coils fused to SpyCatcher002 that could spontaneously self-assemble into different homo-oligomers with valency from 2-7 (Fig. 6a). oDi would represent a dimeric oligomer and oTri a trimeric oligomer and so on.

For oDi, oTri and oHex, we selected coiled coils that were previously computationally designed by the Woolfson laboratory, based on knowledge of key side-chain interactions determining valency and stability, and validated after solid-phase peptide synthesis ${ }^{46,47}$. We increased the repeat number to favor high stability $^{48}$, genetically fused the coiled coils to SpyCatcher002, and expressed constructs in the cytosol of E. coli. The best oTet was the coiled coil from VASP (vasodilator-stimulated phosphoprotein $)^{49}$. For oPent, we selected the coiled coil from COMP (cartilage oligomeric matrix protein $)^{50}$. Finally for oHept, we tested the coiled coil from IMX313, originally adapted from complement $\mathrm{C} 4$ binding protein ${ }^{51}$. These platforms, containing a His-tag, were purified in good yield after Ni-NTA and gelfiltration chromatography. We validated the composition of each of the coiled coil subunits by electrospray ionization mass spectrometry (Supplementary Fig. 7).

The purified SpyCatcher002-oligomers were subjected to dynamic light scattering (DLS) to verify monodispersity and correct assembly. DLS indicated increasing valency from oDi to 
a

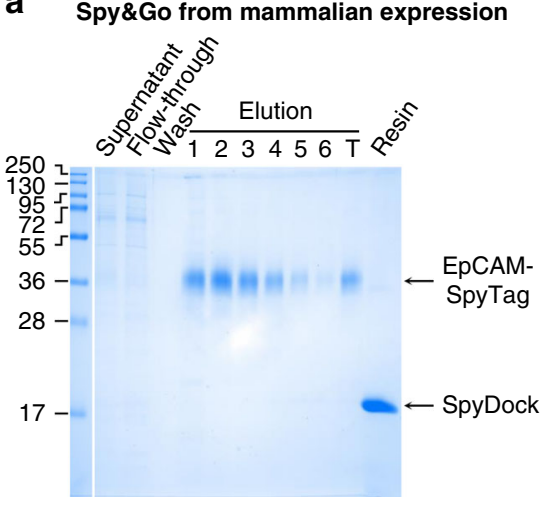

C Spy\&Go from mammalian expression

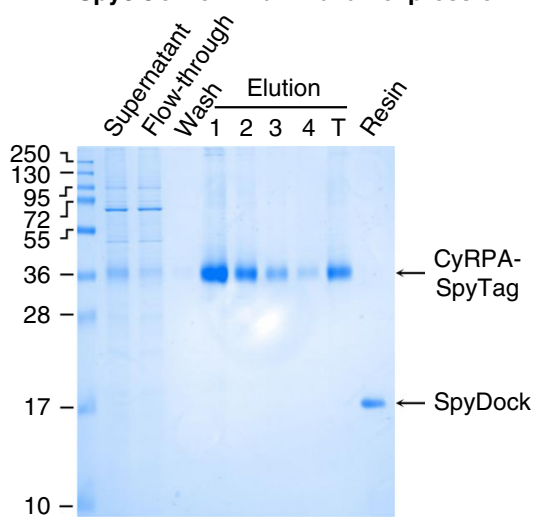

b

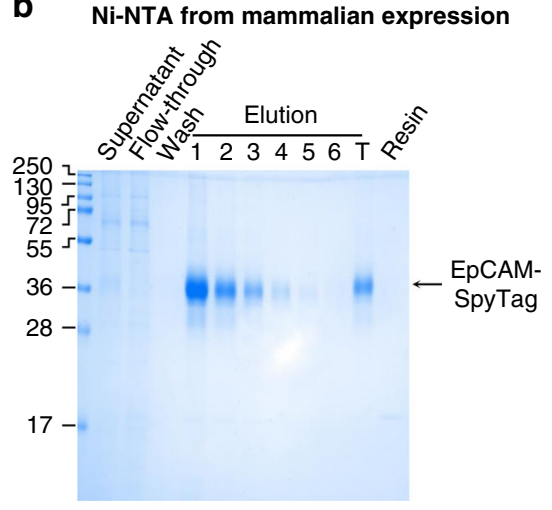

Fig. 5 Spy\&Go from mammalian expression. a HEK293T cells were transfected with the extracellular region of EpCAM fused to SpyTag and a His-tag (EpCAM-SpyTag). EpCAM-SpyTag was purified from the clarified cell supernatant using Spy\&Go. Fractions were analyzed by SDS-PAGE with Coomassie staining. T: total pooled elutions. Resin: resin post-elution. b Ni-NTA purification of EpCAM-SpyTag as in a. c Spy\&Go purification of CyRPA-SpyTag from Expi293HEK cells as in a

oHept based on the increasing hydrodynamic radius $\left(\mathrm{R}_{\mathrm{h}}\right)$ (Fig. 6b). We further analyzed the oligomers by size-exclusion chromatography/multi-angle light scattering (SEC-MALS). SECMALS also analyzes uniformity but additionally characterizes the molecular weight of the assembly. The observed molecular weights were within $10 \%$ of the expected assembled molecular weights (Fig. 6c), suggesting successful assembly by each oligomer from oDi up to oHept.

In our hands, the previously designed tetrameric coiled coil, CC-Tet ${ }^{46}$, when fused to SpyCatcher002, had an observed mass that deviated substantially from the expected mass (Supplementary Fig. 8). We also found that SpyCatcher002 fused to the designed CC-Hept ${ }^{47}$ gave satisfactory assembly (Supplementary Fig. 8), but expressed poorly and was prone to aggregate. Therefore the final Spy oligomerization toolbox was a mixture of computationally designed or natural coiled coils (amino acid sequences shown in Supplementary Fig. 9).

Oligomeric assembly of a nanobody. DR5 is a pro-apoptotic receptor overexpressed on many cancer cells. DR5 activation promotes cell death in response to binding of TNF-related apoptosis-inducing ligand (TRAIL) ${ }^{52}$. DR5 targeting shows promise as a target for cancer therapy ${ }^{53}$. There has been extensive interest in the clustering of DR5 $5^{53-60}$, because dimeric antiDR5 IgG typically causes weak activation of DR5 signaling ${ }^{53}$. Previous attempts at clustering focused on linear chains of antiDR5 agonists. We explored the use of multivalent display of an agonist nanobody (aDR5), to evaluate the effect of increasing nanobody valency on triggering cancer cell death. Nanobodies are a convenient monomeric scaffold, with the single chain easily expressed in E. coli. aDR5 was fused genetically to SpyTag and was purified efficiently via Spy\&Go (Fig. 4d). We then mixed this nanobody with the Spy-coiled coil platforms for convenient modular preparation of dimers, trimers etc. up to heptamers.

aDR5-SpyTag was incubated with each SpyCatcher002oligomer and efficient covalent reaction was confirmed by SDSPAGE. Spy\&Go also enabled us to remove excess aDR5-SpyTag from the mixture, by incubating with Spy\&Go resin to recapture unconjugated aDR5-SpyTag, leaving only oligomer:nanobody complex in the flow-through (Fig. 7a, b).

DR5 signal activation by the nanobody oligomeric series. To assess the potency of these oligomeric SpyCatcher002 platforms, we chose a TRAIL-sensitive human breast cancer cell-line MDAMB-231 34 . We tested a broad range of doses, from 0.1 pM-100 $\mathrm{nM}$ for each SpyCatcher002-oligomer:aDR5-SpyTag and compared death induction after $24 \mathrm{~h}$ of treatment. While monomeric unconjugated aDR5-SpyTag, dimeric, trimeric, and tetrameric conjugates failed to display any cell killing within this range, we observed a clear stoichiometry-dependent dose-response for higher-order aDR5-conjugates (Fig. 7c). All higher-order conjugates (pentameric, hexameric and heptameric) showed potency at sub-nanomolar concentrations. The pentameric complex resulted in killing of $50 \%$ of the cells $\left(\mathrm{EC}_{50}\right)$ at $0.9 \mathrm{nM}$ aDR5. Similarly, the hexamer gave a $\mathrm{EC}_{50}$ of $0.42 \mathrm{nM}$ whereas the heptamer had high potency at $0.31 \mathrm{nM} \mathrm{EC} \mathrm{EC}_{50}$ (Fig. 7c). As a control, we found that unconjugated SpyCatcher002-oligomer constructs did not elicit any dose-dependent loss of cell viability (Fig. 7d). 
a Spy oligomerization toolbox
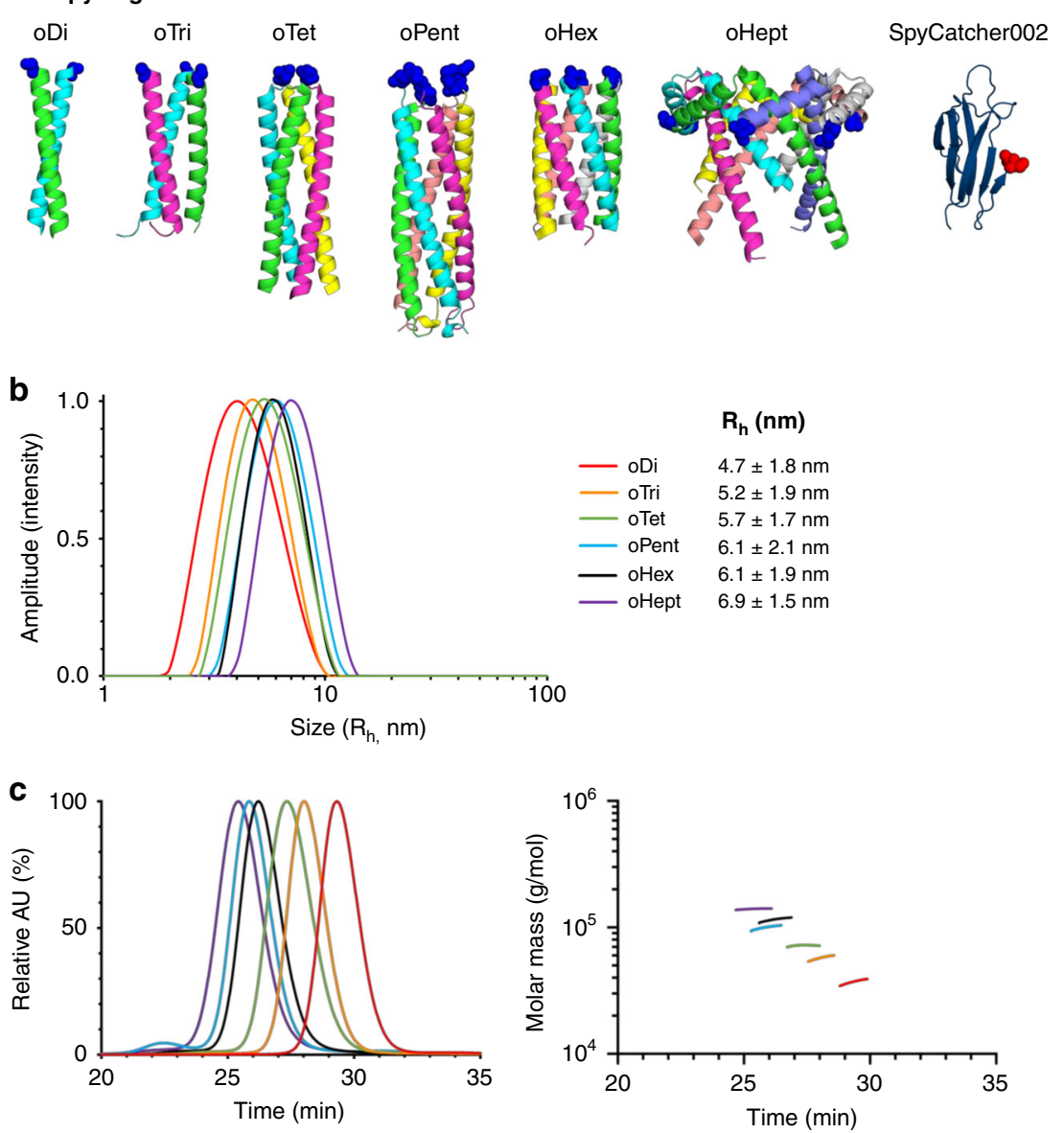

\begin{tabular}{ccc} 
& Observed $\mathbf{M}_{\mathbf{r}}$ & Expected $\mathbf{M}_{\mathbf{r}}(\mathbf{k D a})$ \\
\hline oDi & $37.1 \pm 0.4$ & 40.8 \\
\hline oTri & $57.4 \pm 0.3$ & 61.5 \\
oTet & $79.3 \pm 0.2$ & 85.5 \\
\hline oPent & $99.9 \pm 0.2$ & 109.5 \\
- oHex & $115.5 \pm 0.2$ & 123.5 \\
\hline oHept & $150.5 \pm 0.1$ & 159.4
\end{tabular}

Fig. 6 Construction of oligomeric toolbox. a Spy Oligomerization Toolbox from establishing a panel of coiled coils with valency from 2 to 7 for fusion to SpyCatcher002. The coiled coils are presented with each color representing one chain and the N-terminus colored as a blue ball. The C-terminus of SpyCatcher002, where it will be linked to the coiled coil, is colored as a red ball. b DLS to show assembly of each SpyCatcher002-oligomer, with hydrodynamic radius $\left(R_{\mathrm{h}}\right)$ (mean \pm 1 s.d., $n=10$ ) for each assembly. c SEC-MALS to show assembly of each SpyCatcher002-oligomer. The peak shows the normalized absorbance units (AU) at $280 \mathrm{~nm}$ of the SpyCatcher002-oligomer species from SEC. The horizontal line shows the distribution of molar mass $(\mathrm{g} / \mathrm{mol})$ of the species in the peak from MALS. Expected and observed molecular weight $\left(M_{\mathrm{r}}\right)$ is shown alongside, with error bars representing the uncertainty in fit to the molar mass curve

\section{Discussion}

We have established a system for purification of SpyTag-fused proteins using an immobilized unreactive SpyCatcher variant. The engineering of SpyDock enables efficient binding of SpyTag, facilitating capture and elution of the protein of interest for the different SpyTag iterations. His-tag/Ni-NTA purification has been optimized over decades but our initial results suggest favorable comparison to Spy\&Go for purification from bacteria. We also demonstrated that mammalian proteins can be efficiently purified using SpyTag. As anticipated from the flexible location of SpyTag for covalent reaction with SpyCatcher ${ }^{21,37,38,45,61}$, SpyTag can be located at either terminus of the protein of interest or at an internal site for Spy\&Go purification. We have also shown that Spy\&Go resin can be effectively regenerated and retains its function after storage for months. The current elution conditions for Spy\&Go are unconventional (2.5 M imidazole in Tris-phosphate buffer). Nevertheless, we have observed little aggregation and good yields for the different classes of proteins so far explored. After dialyzing away imidazole, we validated biological activity for mClover3 fluorescence and DR5 agonist cellular activation. We previously demonstrated the tolerance of various enzymes and fluorescent proteins to similar high imidazole concentrations ${ }^{36}$.

Beyond primary purification, Spy\&Go also facilitates the generation of purified nanoassembly preparations. We could remove the excess $\alpha$ DR5-SpyTag from each conjugated SpyCatcher002oligomer:aDR5-SpyTag complex by incubating the mixture with Spy\&Go resin. Since SpyTag reacts irreversibly with SpyCatcher002, the reconstitution reaction renders the conjugated SpyTag unavailable for binding to SpyDock.

Modularity is a defining principle in accelerating biological research, moving from painstaking case-by-case artisanal optimization to an efficient and automatable assembly-line ${ }^{62}$. Previous coiled coils were already individually explored as genetic 
a

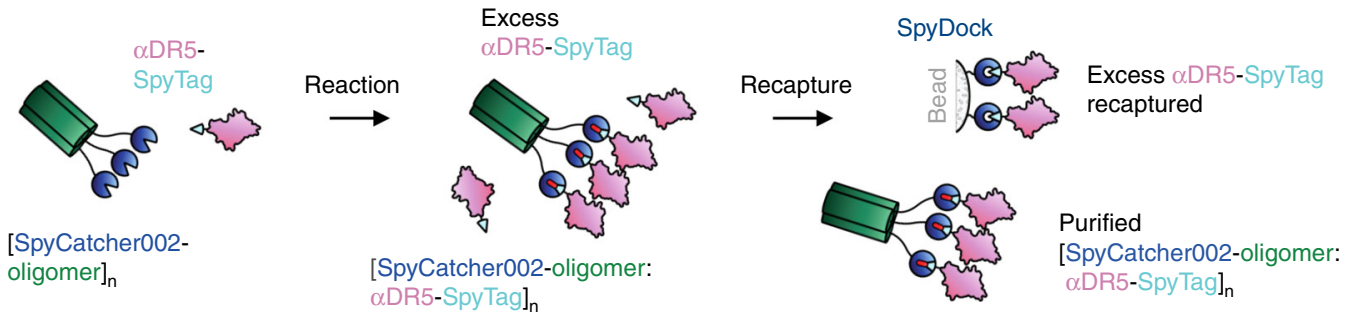

b
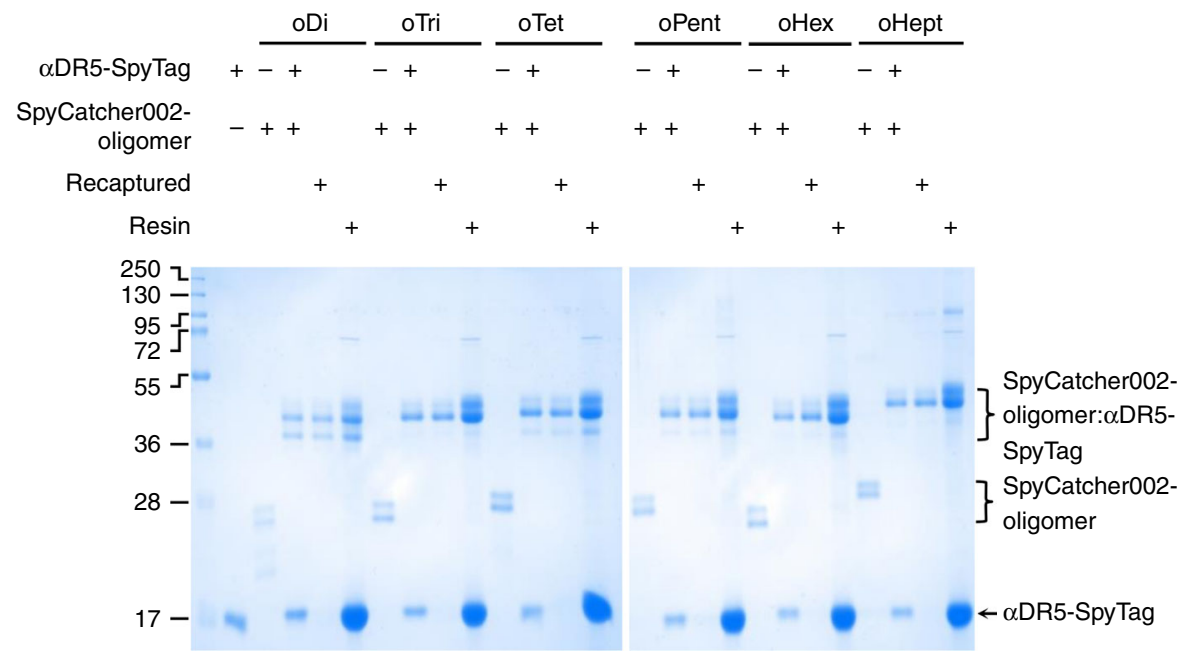

C

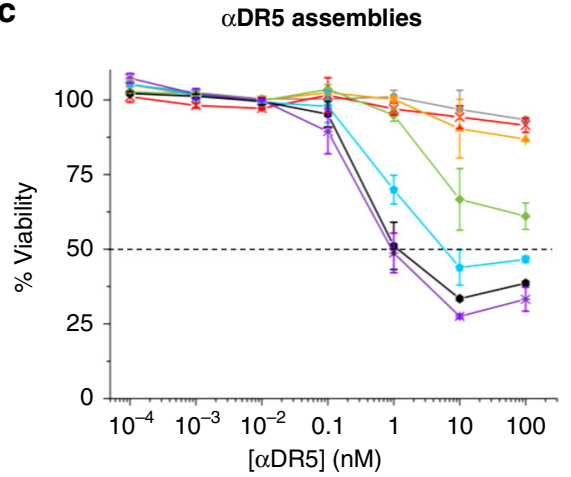

d

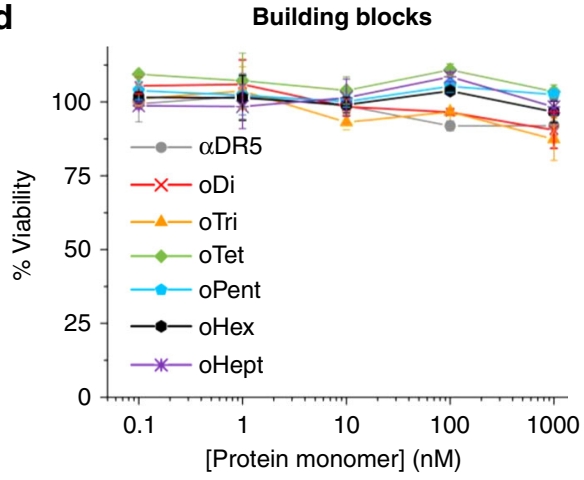

Fig. 7 Oligomer panel tested for cancer cell killing. a Cartoon depicting depletion of free SpyTag-ligand using Spy\&Go resin. b Coupling of SpyTag-fusion to coiled coil series. $\alpha$ DR5-SpyTag was incubated with each SpyCatcherO02-coiled coil and analyzed by SDS-PAGE with Coomassie staining. In Recaptured lanes, excess $\alpha$ DR5-SpyTag was removed from the coiled coil conjugate by an additional passage through Spy\&Go resin. $\mathbf{c}$ Dose-response curve of MDAMB-231 cell viability when treated with different concentrations of $\alpha$ DR5 conjugated to each SpyCatcher002-oligomer platforms. The line at $50 \%$ cell viability shows the cut-off for $\mathrm{EC}_{50}$ calculation. The $x$-axis is normalized to the concentration of $\alpha \mathrm{DR} 5$ monomer. Error bars represent mean \pm 1 s.d., $n=2$. d MDA-MB-231 viability upon incubation as in c with the building blocks of $\alpha$ DR5 alone or coiled coils alone. Error bars represent mean \pm 1 s.d., $n=3$

fusion partners for proteins ${ }^{25,63-65}$, however, optimizations would be needed for each distinct protein $24,37,65$. Examples include heterogeneous populations of 5-7 oligomers instead of a monodisperse heptamer ${ }^{66}$, failed assembly of a trimer-fusion protein $^{67}$, and severe degradation of dimers in E. coli cytosol ${ }^{68,69}$.

The characterized Spy-based oligomerization toolbox can alleviate this problem, separating the expression/folding/posttranslational modification of coiled coils and cargo protein before uniting via SpyTag/SpyCatcher. Spy\&Go-purified aDR5-SpyTag readily reacted to completion with multivalent SpyCatcher002oligomer to form a panel of valency-defined platforms to understand the effect of higher valencies on cellular signaling and the downstream apoptotic effect. Up until now, most multimeric anti-DR5 or soluble TRAIL constructs consist of a linear arrangement linked by simple Gly-Ser linkers extending to 5 repeats ${ }^{55}, 6$ repeats $^{56,57}$ and in one case 8 repeats ${ }^{57}$ of the agonist against DR5 ${ }^{53}$. However, the formation of a linear complex may not mimic the clustering by the native TRAIL to DR5 receptor. A "combody" comprising a genetic fusion of the coiled coil COMP with an agonistic $\alpha$ DR5 was previously made ${ }^{70}$, but direct fusion may not be optimized for other proteins or coiled coil combinations, and no higher valencies were reported. We note that we have characterized SpyCatcher002-coiled coil valency by DLS and SEC-MALS at micromolar concentrations. Both natural and synthetic multimers may start to dissociate as one approaches low nanomolar or picomolar concentrations, where cells may still respond to DR5 clustering but bulk biophysical assays become very difficult ${ }^{46,47}$. In future work, single-molecule assays may be the best way to understand molecular and cellular behavior in this low concentration regime $\mathrm{e}^{71,72}$. 
We envision that the oligomerizing SpyCatcher002-coiled coil platforms can advance the study of valency-dependence on diverse cellular signaling processes ${ }^{73,74}$. By combining Spy\&Go purification with coiled coil nanoassembly, SpyTagging may help to accelerate the exploration and exploitation of protein space.

\section{Methods}

Plasmids and cloning. Constructs were cloned by standard PCR methods and assembled using Gibson assembly. Inserts were verified by Sanger sequencing. pDEST14-SpyCatcher2.1 was derived from pDEST14-SpyCatcher002 23 (GenBank MF974388 and Addgene plasmid ID 102827) with additional A89P, Q97D and K108E mutations (see below). pDEST14-SpyCatcher2.1 S49C E77A (SpyDock) (Supplementary Fig. 2, GenBank MK637462, Addgene plasmid ID 124618) has the organization: $\mathrm{His}_{6}$, SpyCatcher2.1 with E77A S49C mutations, GSSGS. pDEST14SpyCatcher2.1 E77X S49C has the same organization as SpyDock except with E77X mutations instead, with X being D, G, N, Q, S, T, or V. pDEST14-SpyCatcher2.1 E77A N-term Cys has the same organization as SpyDock except with a cysteineanchoring mutation at the $6^{\text {th }}$ amino acid residue preceding SpyCatcher2.1 E77A instead of S49C. pDEST14-SpyCatcher2.1 S55C E77A has the same organization as SpyDock except with a S55C mutation instead of S49C mutation. pET28a-SpyTag$\mathrm{MBP}^{21}$ (Addgene plasmid ID 35050) and pET28a-SpyTag002-MBP ${ }^{23}$ (GenBank MF974389 and Addgene plasmid ID 102831) were as described. pENTR4-EpCAMSpyTag (GenBank MK637463) was derived from pENTR4-EpCAM-SnoopTagJr ${ }^{30}$ (GenBank MH511516) with the organization: tissue plasminogen activator (tPA) secretion leader sequence, extracellular domain of human EpCAM protein (EpCAM; residue 24-265), (GSG) $)_{2}$, SpyTag, GEGS, His 6 . pENTR4-LPTOSCyRPA-SpyTag ${ }^{26}$ (GenBank MH425516) was previously published. pET28aaDR5-SpyTag (GenBank MK637464) was derived from pET28a-SnoopTag- $\alpha$ DR5SpyTag (GenBank KU500643) ${ }^{54}$ with the organization: aDR5 (4E6 nanobody ${ }^{55}$ ), (GGGGS) $)_{2}$, SpyTag. pET28a-SpyTag-mClover3 has the organization: SpyTag, SGGGSG, mClover3 ${ }^{75}$, GSGSGS, His 6 . pET28a-scPvuII-SpyTag (GenBank MK637465) has the organization: His ${ }_{6}$, SSG, PvuII from Proteus vulgaris, GSG, TEV cleavage site, GGSG, SpyTag, GSGG, PvuII. SpyTag along with surrounding spacers was inserted into a loop of the first PvuII between amino acid residues 75 and 76. PvuII constructs had the D58A mutation to block DNA cleavage. pDEST14-SpyCatcher002 was linked to coiled coil inserts consisting of oDi ${ }^{46}$ (GenBank MK637466, Addgene plasmid ID 124661), oTri ${ }^{46}$ (GenBank MK637467, Addgene plasmid ID 124662), oTet ${ }^{49}$ (GenBank MK637468, Addgene plasmid ID 124663), oPent ${ }^{50}$ (GenBank MK637469, Addgene plasmid ID 124664), oHex ${ }^{47}$ (GenBank MK637470, Addgene plasmid ID 124670), oHept ${ }^{51}$ (GenBank MK637471, Addgene plasmid ID 124671), CC-Tet ${ }^{46}$ (GenBank MK637472) or CCHept $^{47}$ (GenBank MK637473). The constructs have the organization: His ${ }_{6}$, DYDIPTT spacer, TEV cleavage site, SpyCatcher002, GSSGSGSGS, coiled coil inserts, GSGSG, C-tag. Coiled coil DNA was synthesized by IDT DNA Technologies (Supplementary Fig. 9). oDi, oTri, oHex, CC-Tet, and CC-Hept have 5 heptad repeats, instead of 4 repeats reported in the literature, to increase the stability of coiled coil assembly ${ }^{48}$.

SpyDock rational design. To complement the increase in positively charged residues of SpyTag002 compared to SpyTag, mutations Q97D and K108E were made on SpyCatcher002 to increase the negatively charged residues, making the SpyDock precursor, SpyCatcher2.1, to improve the electrostatic interaction with the positively-charged SpyTag or SpyTag002 (Fig. 2c). Residues Y83 and E85 within the long A79-A89 loop in SpyCatcher make key interactions with residues Y9 and K10 of SpyTag in the SpyTag/SpyCatcher crystal structure ${ }^{76}$. These wildtype residues were also positively selected during directed evolution to produce SpyTag002, supporting the importance of the residues for rapid isopeptide bond formation ${ }^{23}$. Inclusion of prolines in turns and loops has previously been shown to stabilize proteins ${ }^{36,77-79}$. Hence, the A89P mutation was included to stabilize the A79-A89 loop (Fig. 2c). The E77 was targeted to nullify the isopeptide bond formation, with A, D, G, N, Q, S, T, and V mutations as candidates (Fig. 1). These mutations were postulated to enable better binding and retention of SpyTag to SpyDock during the binding and washing steps, along with easier elution.

Bacterial protein expression. pET28a-SpyTag-MBP, pET28a-SpyTag002-MBP, and pET28a-SpyTag-mClover3 were transformed into chemically competent $E$. coli BL21 (DE3) RIPL (Agilent Technologies). pET28a-scPvuII-SpyTag was transformed into T7 Express lys Y/I ${ }^{\mathrm{q}}$ (NEB). pDEST14-SpyCatcher2.1 S49C E77A (SpyDock), pDEST14-SpyCatcher2.1 S49C E77X variants, pDEST14SpyCatcher2.1 E77A N-term Cys, pDEST14-SpyCatcher2.1 S55C E77A and pDEST14-SpyCatcher002-coiled coil fusions were transformed into chemicallycompetent E. coli C41 (DE3), a kind gift from Anthony Watts (University of Oxford). pET28a-aDR5-SpyTag was transformed into E. coli BL21 (DE3) RIPL containing a gene encoding phosphogluconolactonase, to degrade 6-phosphogluconolactone, which promotes protein gluconoylation ${ }^{80}$. The cells were plated on LB agar supplemented with $50 \mu \mathrm{g} / \mathrm{mL}$ kanamycin (pET28a) or $100 \mu \mathrm{g} / \mathrm{mL}$ ampicillin (pDEST14). For $\alpha$ DR5-SpyTag, $34 \mu \mathrm{g} / \mathrm{mL}$ chloramphenicol was added alongside kanamycin throughout. The plates were incubated at $37^{\circ} \mathrm{C}$ overnight until colonies were observed.

Single colonies of pET28a-SpyTag-MBP, pET28a-SpyTag002-MBP, pET28aSpyTag-mClover3, pET28a-scPvuII-SpyTag, and pDEST14-SpyDock, all variants of pDEST14-SpyCatcher2.1 S49C E77X, pDEST14-SpyCatcher2.1 E77A N-term Cys, pDEST14-SpyCatcher2.1 E77A S55C, and all variants of pDEST14SpyCatcher002-coiled coils were picked and inoculated into $10 \mathrm{~mL} \mathrm{LB}$ medium supplemented with $50 \mu \mathrm{g} / \mathrm{mL}$ kanamycin (pET28a) or $100 \mu \mathrm{g} / \mathrm{mL}$ ampicillin (pDEST14), incubated at $37^{\circ} \mathrm{C}$ with shaking at $200 \mathrm{rpm}$ for $16 \mathrm{~h}$. The cultures were then inoculated into $1 \mathrm{~L} \mathrm{LB}$ supplemented with $50 \mu \mathrm{g} / \mathrm{mL}$ kanamycin (pET28a) or $100 \mu \mathrm{g} / \mathrm{mL}$ ampicillin (pDEST14) and $0.8 \%$ (w/v) glucose (except for pDEST14SpyCatcher002-coiled coils), incubated at $37^{\circ} \mathrm{C}$ with shaking at $200 \mathrm{rpm}$ until $A_{600}$ $0.5-0.6$, when the cultures were induced with $0.42 \mathrm{mM}$ isopropyl $\beta$-D-1thiogalactopyranoside (IPTG) (Fluorochem). Cultures of pET28a-SpyTag-MBP, pET28a-SpyTag002-MBP, pET28a-SpyTag-mClover3, pET28a-scPvuII-SpyTag, and pDEST14-SpyDock, all variants of pDEST14-SpyCatcher2.1 S49C E77X, pDEST14-SpyCatcher2.1 E77A N-term Cys, and pDEST14-SpyCatcher2.1 E77A S55C were grown further for $4 \mathrm{~h}$ with shaking at $200 \mathrm{rpm}$ at $30^{\circ} \mathrm{C}$. Cultures of pDEST14-SpyCatcher002-oDi, pDEST14-SpyCatcher002-oTri, pDEST14SpyCatcher002-oTet, pDEST14-SpyCatcher002-oPent, and pDEST14SpyCatcher002-CC-Tet were grown further for $16 \mathrm{~h}$ with shaking at $200 \mathrm{rpm}$ at $22^{\circ} \mathrm{C}$. Cultures of pDEST14-SpyCatcher002-oHex, pDEST14-SpyCatcher002oHept and pDEST14-SpyCatcher002-CC-Hept were grown for $4 \mathrm{~h}$ with shaking at $200 \mathrm{rpm}$ at $37^{\circ} \mathrm{C}$.

A single colony of pET28a- $\mathrm{DDR} 5$-SpyTag was picked and inoculated into $1 \mathrm{~L}$ auto-induction medium (AIMLB0205 from Formedium) supplemented with $50 \mu \mathrm{g} /$ $\mathrm{mL}$ kanamycin and $34 \mu \mathrm{g} / \mathrm{mL}$ chloramphenicol, incubated at $30^{\circ} \mathrm{C}$ with shaking at $200 \mathrm{rpm}$ for $24 \mathrm{~h}$. All E. coli-expressed proteins were harvested by centrifugation at $4000 \times g$ for $15 \mathrm{~min}$ at $4{ }^{\circ} \mathrm{C}$ prior to purification.

Mammalian protein expression. EpCAM-SpyTag was expressed in adherent HEK293T cells. HEK293T cells were cultured in T175 adhesive culture flasks (Corning) with Dulbecco's Modified Eagle's Medium (DMEM) (Sigma-Aldrich) high glucose with $10 \%$ (v/v) Fetal Bovine Serum (Sigma-Aldrich), 2 mM L-glutamine, $100 \mathrm{U} / \mathrm{mL}$ penicillin, and $100 \mu \mathrm{g} / \mathrm{mL}$ streptomycin (Thermo Fisher Scientific) at $37^{\circ} \mathrm{C}$ with $5 \% \mathrm{CO}_{2}$. Before transfection, the cells were seeded into a T875 5-layer flask (Corning) and upon reaching 50\% confluency, they were transferred into serum-free media (DMEM, $2 \mathrm{mM}$ glutamine, $50 \mathrm{U} / \mathrm{mL}$ penicillin, $25 \mathrm{mM}$ HEPES added) and mixed with $30 \mu \mathrm{g}$ pENTR4-EpCAM-SpyTag plasmid per $7.5 \mathrm{~mL}$ of media for each flask layer. After $15 \mathrm{~min}, 2.5 \mathrm{~mL}$ media containing $36 \mu \mathrm{g} / \mathrm{mL}$ polyethyleneimine (Sigma-Aldrich) was added to each layer. $10 \mathrm{~mL}$ media containing $4.4 \mu \mathrm{M}$ valproic acid (Sigma-Aldrich), $100 \mathrm{U} / \mathrm{mL}$ penicillin, and $100 \mu \mathrm{g} / \mathrm{mL}$ streptomycin was added to each layer 16-20 h later. Cells were then incubated at $37^{\circ} \mathrm{C}$ with $5 \% \mathrm{CO}_{2}$ for another 6 days.

CyRPA-SpyTag was expressed in suspension Expi293HEK cells (Thermo Fisher Scientific). Expi293HEK cells were cultured in Expi293 expression media (Thermo Fisher Scientific) with $50 \mathrm{U} / \mathrm{mL}$ penicillin/streptomycin at $37^{\circ} \mathrm{C}$ with $7 \% \mathrm{CO}_{2}$ shaking at 110-125 rpm. Transient transfection of pENTR4-LPTOS-CyRPASpyTag was done using the ExpiFectamine 293 transfection kit (Thermo Fisher Scientific). Cells at a density of $2.5 \times 10^{6}$ cells $/ \mathrm{mL}$ were transfected with $2.7 \mu \mathrm{L}$ ExpiFectamine 293 Reagent per $1 \mu \mathrm{g}$ of pENTR4-LPTOS-CyRPA-SpyTag plasmid. After 16-18 h, ExpiFectamine transfection enhancers (Thermo Fisher Scientific) were added and the cell supernatant was harvested 4 days post-transfection.

The cell supernatants were harvested by addition of cOmplete ${ }^{\mathrm{T} \omega}$, Mini, EDTAfree Protease Inhibitor Cocktail (Roche), centrifuged at $1000 \times g$ for $3 \mathrm{~min}$, and filtered through a $0.45 \mu \mathrm{m}$ syringe filter to remove cell debris. $2.5 \%$ of $10 \times \mathrm{Ni}-\mathrm{NTA}$ or $10 \times \mathrm{TP}$ buffer $(250 \mathrm{mM}$ orthophosphoric acid adjusted to $\mathrm{pH} 7.0$ with Tris base) was added for $\mathrm{pH}$ adjustment before affinity chromatography purification.

Protein purification by Ni-NTA. Purifications were done at $4{ }^{\circ} \mathrm{C}$ throughout. All E. coli-grown constructs (except aDR5-SpyTag, scPvuII-SpyTag, SpyTag-mClover3, SpyCatcher002-oHex, SpyCatcher002-oHept and SpyCatcher002-CC-Hept) were resuspended in $1 \times \mathrm{Ni}-\mathrm{NTA}$ buffer $(50 \mathrm{mM}$ Tris- $\mathrm{HCl}, 300 \mathrm{mM} \mathrm{NaCl} \mathrm{pH} \mathrm{7.8}$; SpyDock along with all variants of SpyCatcher2.1 S49C E77X, SpyCatcher2.1 E77A N-term Cys, SpyCatcher2.1 E77A S55C and SpyCatcher002-oPent had additional $10 \mathrm{mM}$ 2-mercaptoethanol) with cOmplete ${ }^{\mathrm{Tm}}$, Mini, EDTA-free Protease Inhibitor Cocktail and $1 \mathrm{mM}$ phenylmethylsulfonyl fluoride (PMSF). Cells were lysed by addition of $100 \mu \mathrm{g} / \mathrm{mL}$ lysozyme (Sigma-Aldrich) and $2 \mathrm{U} / \mathrm{mL}$ benzonase (SigmaAldrich). The lysate was rotated at $25^{\circ} \mathrm{C}$ for $30 \mathrm{~min}$ and sonicated on ice for $4 \times 1$ min with $1 \mathrm{~min}$ rest period at $50 \%$ duty cycle. Clarified cell lysates were centrifuged at $30,000 \mathrm{~g}$ for $30 \mathrm{~min}$ before incubation with Ni-NTA beads (Qiagen) on a rotary shaker for $1 \mathrm{~h}$. The lysate-bead mixture was added onto a polyprep gravity column and washed with 20 packed resin volumes of Ni-NTA wash buffer $(10 \mathrm{mM}$ imidazole in Ni-NTA buffer, $\mathrm{pH} 7.8$; SpyDock, all variants of SpyCatcher2.1 S49C E77X, SpyCatcher2.1 E77A N-term Cys, SpyCatcher2.1 E77A S55C and SpyCatcher002-oPent had $10 \mathrm{mM}$ 2-mercaptoethanol for the first 10 packed resin volumes; SpyCatcher002 coiled coil fusions used $75 \mathrm{mM}$ imidazole in Ni-NTA buffer) and eluted with Ni-NTA elution buffer $(200 \mathrm{mM}$ imidazole in Ni-NTA buffer, pH 7.8; SpyCatcher002 coiled coil fusions used $350 \mathrm{mM}$ imidazole in NiNTA buffer) at $4^{\circ} \mathrm{C}$. Elutions were monitored by $A_{280}$ and stopped once $A_{280}$ was 
<1.0. Proteins were dialyzed against $20 \mathrm{mM}$ Tris- $\mathrm{HCl} \mathrm{pH} 8.0$ and concentrated, if necessary, using Vivaspin centrifugal concentrator $5 \mathrm{kDa}$ cutoff (GE Healthcare).

SpyDock was further purified on a HiTrap Q HP anion exchange

chromatography column (GE Healthcare) connected to an ÄKTA Pure 25 (GE Healthcare) fast protein liquid chromatography (FPLC) system at $4{ }^{\circ} \mathrm{C}$. The protein was eluted with a linear gradient of $0.2-0.35 \mathrm{M} \mathrm{NaCl}$ (in $10 \mathrm{mM}$ Tris- $\mathrm{HCl} \mathrm{pH} 8.0$ with $1 \mathrm{mM}$ dithiothreitol) at a flow rate of $2 \mathrm{~mL} / \mathrm{min}$ at $4{ }^{\circ} \mathrm{C}$. Peak fractions were

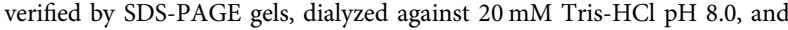
concentrated using Vivaspin centrifugal concentrator $5 \mathrm{kDa}$ cutoff. Typical yield for SpyDock after Ni-NTA and ionic exchange chromatography is approximately $28 \mathrm{mg} / \mathrm{L}$ culture

All SpyCatcher002 coiled coil fusions were further purified by gel filtration chromatography on a pre-equilibrated HiLoad 16/600 Superdex 200 pg column connected to ÄKTA Pure 25 FPLC system. The mobile phase was $50 \mathrm{mM}$ Tris- $\mathrm{HCl}$, $150 \mathrm{mM} \mathrm{NaCl} \mathrm{pH} 8.0$ at a flow-rate of $1 \mathrm{~mL} / \mathrm{min}$ at $4{ }^{\circ} \mathrm{C}$ with $A_{280}$ monitored throughout. Fractions were collected corresponding to the size of the oligomeric SpyCatcher002 coiled coil complex: SpyCatcher002-oDi $(75-78 \mathrm{~mL})$, SpyCatcher002-oTri (69-72 mL), SpyCatcher002-oTet (66-70 mL), SpyCatcher002-oPent (62-65 mL), SpyCatcher002-oHex (61-65 mL), SpyCatcher002-oHept $(56-60 \mathrm{~mL})$. All SpyCatcher002-coiled coil fusions had a yield of approximately $3 \mathrm{mg} / \mathrm{L}$ culture, following Ni-NTA and gel filtration chromatography.

Protein purification by refolding. SpyCatcher002-oHex, SpyCatcher002-oHept, and SpyCatcher002-CC-Hept were found in inclusion bodies and so were purified by refolding. Cells were resuspended in $100 \mathrm{mM}$ Tris- $\mathrm{HCl} \mathrm{pH} 8.0$ with cOmplete $\mathrm{e}^{\mathrm{wn}}$, Mini, EDTA-free Protease Inhibitor Cocktail and $1 \mathrm{mM}$ PMSF. Cells were lysed by addition of $100 \mu \mathrm{g} / \mathrm{mL}$ lysozyme and $2 \mathrm{U} / \mathrm{mL}$ benzonase and rotated at $25^{\circ} \mathrm{C}$ for $30 \mathrm{~min}$. There was one freeze-thaw cycle from $-80^{\circ} \mathrm{C}$ to $25^{\circ} \mathrm{C}$, followed by addition of $0.5 \%(\mathrm{v} / \mathrm{v})$ Triton X-100 and sonication on ice for $4 \times 1 \mathrm{~min}$ with $1 \mathrm{~min}$ rest period at $50 \%$ duty cycle. Clarified cell lysates were centrifuged at $30,000 \times g$ for $30 \mathrm{~min}$. The cell pellet was washed with $2 \times \mathrm{PBS}+0.1 \%(\mathrm{v} / \mathrm{v})$ Triton X-100 and then $2 \times$ PBS, with centrifugation at $25,000 \times g$ for 20 min between steps. The inclusion body pellet was resuspended in $8 \mathrm{M}$ urea in $50 \mathrm{mM}$ Tris- $\mathrm{HCl} \mathrm{pH} 8.0$ and refolded by diluting 50 -fold into refolding buffer of $0.1 \mathrm{M}$ Tris- $\mathrm{HCl} \mathrm{pH} 8.0,0.4 \mathrm{M}$ $\mathrm{L}$-arginine and $0.1 \mathrm{M}$ PMSF (for SpyCatcher002-oHept, $5 \mathrm{mM}$ reduced glutathione and $0.5 \mathrm{mM}$ oxidized glutathione were present) for $40 \mathrm{~h}$. The mixture was filtered through a $0.45-\mu \mathrm{m}$ membrane before incubation with Ni-NTA beads on a rotary shaker for $1 \mathrm{~h}$. The lysate-bead mixture was added onto a polyprep gravity column and washed with 20 resin volumes of Ni-NTA wash buffer (with $75 \mathrm{mM}$ imidazole; SpyCatcher002-oHept had $10 \mathrm{mM}$ 2-mercaptoethanol for the first 10 packed resin volumes) and eluted with Ni-NTA elution buffer (with $350 \mathrm{mM}$ imidazole) at $4{ }^{\circ} \mathrm{C}$. Elutions were monitored by $A_{280}$ and stopped once $A_{280}$ was $<1.0$. Proteins were dialyzed against $20 \mathrm{mM}$ Tris- $\mathrm{HCl} \mathrm{pH} 8.0$ and concentrated to suitable working concentrations, if needed, using Vivaspin centrifugal concentrator $5 \mathrm{kDa}$ cutoff (GE Healthcare).

\section{SpyCatcher2.1 E77A variants coupling to SulfoLink resin. Purified Spy-}

Catcher2.1 E77A with various cysteine anchoring residues (N-term Cys, S55C, and S49C) were coupled to SulfoLink Coupling Resin (Thermo Fisher Scientific) according to the manufacturer's protocol at $25^{\circ} \mathrm{C}$. In short, $20 \mathrm{mg}$ of protein for every $1 \mathrm{~mL}$ of resin was reduced by $1 \mathrm{mM}$ tris(2-carboxyethyl)phosphine (TCEP) (Fluorochem, UK) for $30 \mathrm{~min}$, prior to mixing end-over-end with equilibrated resin for $15 \mathrm{~min}$ and leaving to stand for $30 \mathrm{~min}$ covered by foil. Protein flow-through was aspirated and resin was washed with 10 resin volumes of coupling buffer (50 $\mathrm{mM}$ Tris- $\mathrm{HCl}, 5 \mathrm{mM}$ EDTA, $\mathrm{pH}$ 8.5). The resin was blocked with $50 \mathrm{mM} \mathrm{L}-$ cysteine- $\mathrm{HCl}$ in coupling buffer (MP Biomedicals), mixed end-over-end for $15 \mathrm{~min}$, and left to stand for $30 \mathrm{~min}$. The resin was then washed with 10 resin volumes of $1 \mathrm{M} \mathrm{NaCl}$, and stored in 1xTris-phosphate (TP) buffer ( $25 \mathrm{mM}$ orthophosphoric acid adjusted to $\mathrm{pH} 7.0$ with Tris base), before adding $0.05 \%$ (w/v) $\mathrm{NaN}_{3}$ and storing at $4^{\circ} \mathrm{C}$.

Isothermal titration calorimetry. SpyDock was trapped as a monomer by reduction with $2.5 \mathrm{mM}$ TCEP in $50 \mathrm{mM}$ Tris- $\mathrm{HCl}$ with $5 \mathrm{mM}$ EDTA at $\mathrm{pH} 8.5$ and by cysteine modification with $20 \mathrm{mM}$ iodoacetamide in $50 \mathrm{mM}$ Tris- $\mathrm{HCl}$ with 5 mM EDTA at $\mathrm{pH} 8.5$ for $30 \mathrm{~min}$ in the dark to produce carbamidomethylated SpyDock. Excess TCEP and iodoacetamide were removed by dialysis. SpyTagMBP, SpyTag002-MBP and the modified SpyDock were subsequently dialyzed twice into $20 \mathrm{mM}$ HEPES pH 7.0 with $150 \mathrm{mM} \mathrm{NaCl}$. Experiments were carried out using a Microcal PEAQ-isothermal titration calorimetry (ITC) calorimeter (Malvern) at $25^{\circ} \mathrm{C}$ in $20 \mathrm{mM}$ HEPES pH 7.0 with $150 \mathrm{mM} \mathrm{NaCl} .20 \mu \mathrm{M}$ SpyDock was used in the cell and titrated with 20 injections of $210 \mu \mathrm{M}$ SpyTag-MBP or SpyTag002-MBP in the syringe. Analyses were carried out using a 1:1 binding model with the MicroCal PEAQ-ITC Analysis software version 1.1.0.1262.

Purification by Spy\&Go. To determine the best cysteine anchoring site, $50 \mu \mathrm{L}$ packed resin with SpyCatcher2.1 E77A N-term Cys, S55C, or S49C was mixed with $500 \mu \mathrm{L}$ TP buffer containing $0.09 \mathrm{mg}(10 \times$ lower than SpyCatcher2.1 E77A available on resin) of Ni-NTA-purified SpyTag-MBP in an Eppendorf tube through batch chromatography. The low amount of SpyTag-MBP introduced was to test the sensitivity of Spy\&Go purification. The protein was mixed with the resin for $1 \mathrm{~h}$ with tumbling at $4^{\circ} \mathrm{C}$. Standard Spy\&Go batch chromatography purification is as follows: the resin was washed $4 \times$ with 10 resin volumes of TP buffer, with incubation at $4{ }^{\circ} \mathrm{C}$ shaking at $1,200 \mathrm{rpm}$ for $3 \mathrm{~min}$. Resin was then centrifuged at $4000 \times \mathrm{g}$ for $3 \mathrm{~min}$ at $4^{\circ} \mathrm{C}$. The protein was eluted with $4 \times 1.5$ resin volume of elution buffer ETP (2.5 M imidazole in TP buffer).

For purification of SpyTag-MBP and SpyTag002-MBP from lysate, $0.09 \mathrm{mg}$ of the Ni-NTA-purified proteins were added into $\sim 0.25 \mathrm{~g}$ wet cell weight of induced BL21 (DE3) RIPL cleared lysate dissolved in $500 \mu \mathrm{L}$ TP buffer in an Eppendorf tube containing $50 \mu \mathrm{L}$ packed Spy\&Go resin. The protein-lysate was mixed with the resin for $1 \mathrm{~h}$ tumbling at $4^{\circ} \mathrm{C}$. Standard Spy\&Go batch chromatography purification was performed to purify the proteins but washed with wash buffer WTP (500 mM imidazole in TP buffer).

EpCAM-SpyTag was purified from the supernatant of HEK293T cells by mixing $50 \mathrm{~mL}$ of the supernatant with $0.5 \mathrm{~mL}$ packed Spy\&Go resin. CyRPA-SpyTag was purified from the supernatant of Expi293HEK cells by mixing $3.5 \mathrm{~mL}$ of the supernatant with $50 \mu \mathrm{L}$ of packed Spy\&Go resin. Both were rolling for $1 \mathrm{~h}$ at $4{ }^{\circ} \mathrm{C}$. The mixture was then purified by standard gravity column chromatography: resin was washed $4 \times$ with 10 resin volumes of TP buffer and eluted with $6 \times 1$ resin volume of ETP buffer $(4 \times 1$ resin volume for CyRPA-SpyTag). Typical yield for EpCAM-SpyTag after Spy\&Go purification was approximately $2.9 \mathrm{mg} / \mathrm{L}$ culture and for CyRPA-SpyTag was approximately $8.9 \mathrm{mg} / \mathrm{L}$ culture.

For comparison with Ni-NTA resin, the methods described were performed with equivalent volume of packed Ni-NTA resin with the following changes:

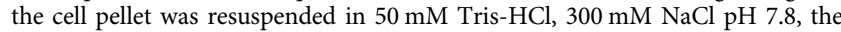
wash buffer was Ni-NTA wash buffer $(30 \mathrm{mM}$ imidazole for SpyTag-MBP, $10 \mathrm{mM}$ imidazole for EpCAM-SpyTag) and elution was carried out with Ni-NTA elution buffer.

For purification of aDR5-SpyTag, the cell pellet from $1 \mathrm{~L}$ of culture was centrifuged and resuspended in $10 \mathrm{~mL}$ TP buffer with $1 \mathrm{mM}$ dithiothreitol, cOmplete $^{\mathrm{m}}$, Mini, EDTA-free Protease Inhibitor Cocktail and $1 \mathrm{mM}$ PMSF. Cells were lysed by addition of $100 \mu \mathrm{g} / \mathrm{mL}$ lysozyme and $2 \mathrm{U} / \mathrm{mL}$ benzonase rotated at $25^{\circ} \mathrm{C}$ for $30 \mathrm{~min}$, and subsequently sonicated on ice for $4 \times 1 \mathrm{~min}$ at $50 \%$ duty cycle and spun down at $30,000 \mathrm{~g}$ to remove cell debris. The cleared lysate was mixed with $1 \mathrm{~mL}$ of Spy\&Go resin rolling for $1 \mathrm{~h}$ at $4^{\circ} \mathrm{C}$. Standard gravity column chromatography purification was performed to purify aDR5-SpyTag with washes using WTP buffer.

For purification of scPvuII-SpyTag and SpyTag-mClover3, the cell pellet from $0.25 \mathrm{~L}$ of culture was lysed with $5 \mathrm{~mL}$ BugBuster reagent per gram of wet cell weight in the presence of $100 \mu \mathrm{g} / \mathrm{mL}$ lysozyme and $2 \mathrm{U} / \mathrm{mL}$ benzonase. The sample was incubated standing at room temperature for $20 \mathrm{~min}$. After spinning down at $30,000 \times g$ to remove cell debris, the cleared lysate was mixed with Spy\&Go resin with rolling for $1 \mathrm{~h}$ at $4{ }^{\circ} \mathrm{C}$. Standard gravity column chromatography purification was performed using WTP buffer for washes and $4 \times 1$ resin volume for elution.

SpyTag-protein and SpyCatcher reconstitution reaction. To investigate any formation of covalent bond, $5 \mu \mathrm{M}$ SpyCatcher2.1 S49C with E77X (X being A, D G, N, Q, S, T, or V) was reacted with $2 \times$ molar excess of SpyTag-MBP $(10 \mu \mathrm{M})$ at $25^{\circ} \mathrm{C}$ for $24 \mathrm{~h}$ in TP buffer. Reaction was quenched with SDS-PAGE loading buffer [0.23 M Tris $\mathrm{HCl} \mathrm{pH} \mathrm{6.8,24 \%} \mathrm{(v/v)} \mathrm{glycerol,} 120 \mu \mathrm{M}$ bromophenol blue, $0.23 \mathrm{M}$ SDS, $100 \mathrm{mM} \mathrm{2-mercaptoethanol]} \mathrm{and} \mathrm{heating} \mathrm{at} 95^{\circ} \mathrm{C}$ for $5 \mathrm{~min}$ in a Bio-Rad C1000 thermal cycler.

To form SpyCatcher002-oligomer: $\alpha$ DR5-SpyTag, $100 \mu \mathrm{M}$ monomeric concentration of SpyCatcher002-oligomer was mixed with $300 \mu \mathrm{M}$ aDR5-SpyTag in $200 \mu \mathrm{L}$ total volume overnight at $25^{\circ} \mathrm{C}$ in $50 \mathrm{mM}$ Tris- $\mathrm{HCl}, 150 \mathrm{mM} \mathrm{NaCl}$, $\mathrm{pH}$ 8.0. Excess aDR5-SpyTag was removed by recapturing using Spy\&Go resin by incubating the reaction mixture with $50 \mu \mathrm{L}$ Spy\&Go resin for $2 \mathrm{~h}$ at room temperature with mixing end-over-end. The mixture was then loaded onto a Micro Bio-Spin column (Bio-Rad) and the conjugated SpyCatcher002-oligomer:aDR5SpyTag was recovered by centrifugation at $300 \mathrm{~g}$ for $1 \mathrm{~min}$ at $4{ }^{\circ} \mathrm{C}$ into a microcentrifuge tube. This process was repeated once. The protein concentrations were measured by Proteoquant BCA assay (Expedeon).

SDS-PAGE and protein purity quantification. SDS-PAGE was performed using $16 \%$ Tris-glycine gels in an XCell SureLock system (Thermo Fisher Scientific). Samples were loaded with final concentration of 1x SDS-PAGE loading buffer. For reduced samples, $100 \mathrm{mM}$ 2-mercaptoethanol was added. SDS-PAGE gels were run at $190 \mathrm{~V}$ in $25 \mathrm{mM}$ Tris- $\mathrm{HCl}, 192 \mathrm{mM}$ glycine, $0.1 \%$ (w/v) SDS, pH 8.5. Gels were stained with InstantBlue Coomassie stain (Expedeon), destained with MilliQ water, and imaged using ChemiDoc XRS imager and analyzed with ImageLab (version 6.0.1) (Bio-Rad). In ImageLab, low sensitivity band detection in the final eluted lane $(\mathrm{T})$ was calculated and compared with the protein control lane (Protein) at background subtraction of disk size $2 \mathrm{~mm}$. Percentage purity is defined as $100 \times$ [target protein Band \% in lane T/target protein Band \% in lane Protein].

Regeneration of Spy\&Go resin. Lysate from bacterial expression of SpyTag-MBP was purified using $0.5 \mathrm{~mL}$ Spy\&Go resin as above. The resin was equilibrated with $2 \times 10$ packed resin volumes of TP buffer before regeneration. Spy\&Go resin was 
then regenerated at $25^{\circ} \mathrm{C}$ by incubating with $3 \times 10$ packed resin volumes of $4 \mathrm{M}$ imidazole in TP buffer $\mathrm{pH} 7.0$ for 5 min each time, washing with $1 \times \mathrm{TP}$ buffer, incubating with $3 \times 10$ packed resin volumes of $6 \mathrm{M}$ guanidine hydrochloride $\mathrm{pH}$ 2.0 for 5 min each time, washing with $1 \times \mathrm{TP}$ buffer, incubating with $3 \times 10$ packed resin volumes of $0.1 \mathrm{M} \mathrm{NaOH}$ for 1 min each time, and washing with $2 \times \mathrm{TP}$ buffer before storage in $20 \%(\mathrm{v} / \mathrm{v})$ ethanol in MilliQ water at $4{ }^{\circ} \mathrm{C}$. Supernatant from each stage was analyzed by SDS-PAGE with Coomassie staining. New resin, resin preregeneration and regenerated resin were also analyzed by boiling in SDS-PAGE loading buffer, followed by SDS-PAGE with Coomassie staining. Lysate from bacterial expression of $\alpha$ DR5-SpyTag was added to new resin or regenerated resin and purified using the standard Spy\&Go protocol, before analysis by SDS-PAGE with Coomassie staining. To test capture after storage, Spy\&Go resin was stored in $20 \%(\mathrm{v} / \mathrm{v})$ ethanol for 12 weeks at at $4{ }^{\circ} \mathrm{C}$, before purification of SpyTag-MBP from bacterial lysate following the standard protocol.

Mass spectrometry. An Agilent RapidFire 365 platform, coupled to an Agilent 6550 Accurate-Mass Quadrupole Time-of-Flight (Q-TOF) mass spectrometer, was used to perform intact protein mass spectrometry in positive ion mode with a jetstream electrospray ion source (Agilent). Proteins with disulfide bonds were reduced with $2.5 \mathrm{mM}$ TCEP in $50 \mathrm{mM}$ Tris- $\mathrm{HCl}$ with $5 \mathrm{mM}$ EDTA at $\mathrm{pH} 8.5$ for 1 $\mathrm{h}$ before treatment with formic acid. Protein samples at $10 \mu \mathrm{M}$ in $50 \mu \mathrm{L}$ volume were prepared on a 384-well polypropylene plate (Greiner) and acidified to $1 \%$ (v/ v) formic acid. Samples were aspirated under vacuum for $0.4 \mathrm{~s}$ on the RapidFire sampling platform and loaded onto a $\mathrm{C} 4$ solid-phase extraction cartridge. Following washes with $0.1 \%(\mathrm{v} / \mathrm{v})$ formic acid at $1.5 \mathrm{~mL} / \mathrm{min}$ flow-rate for $5.5 \mathrm{~s}$, the samples were eluted to the mass spectrometer with deionized water containing $85 \%$ $(\mathrm{v} / \mathrm{v})$ acetonitrile and $0.1 \%(\mathrm{v} / \mathrm{v})$ formic acid at $1.25 \mathrm{~mL} / \mathrm{min}$ for $5.5 \mathrm{~s}$. The cartridge was equilibrated with deionized water for $0.5 \mathrm{~s}$. Nitrogen drying gas for the ionization source was operated at $13 \mathrm{~L} / \mathrm{min}$ at $225^{\circ} \mathrm{C}$, with the jet stream sheath gas at a flow-rate of $12 \mathrm{~L} / \mathrm{min}$ at $350^{\circ} \mathrm{C}$ and the nozzle voltage at $1500 \mathrm{~V}$. Data analysis was done using Mass Hunter Qualitative Analysis software version 7.0, with the protein ionization data deconvoluted using the maximum entropy algorithm. Predicted mass was calculated using ExPASy ProtParam, based on all disulfide bonds being reduced and cleavage of the $\mathrm{N}$-terminal formylmethionine.

SEC-MALS. Samples were prepared at $2 \mathrm{mg} / \mathrm{mL}$ in $100 \mu \mathrm{L}$ in $50 \mathrm{mM}$ Tris- $\mathrm{HCl}$, $150 \mathrm{mM} \mathrm{NaCl} \mathrm{pH} 8.0$ and injected into a Superdex $200 \mathrm{HR}$ 10/30 column (GE Healthcare) at $25^{\circ} \mathrm{C}$ at a flow-rate of $0.5 \mathrm{~mL} / \mathrm{min}$ connected to a Shimadzu HPLC system comprising LC-20AD pump, SIL-20AC autosampler and SPD20A UV/Vis detector with $50 \mathrm{mM}$ Tris- $\mathrm{HCl}, 150 \mathrm{mM} \mathrm{NaCl} \mathrm{pH} 8.0$ as running buffer Light scattering was detected by a Wyatt Dawn HELEOS-II 8-angle light scattering detector and Wyatt Optilab rEX refractive index monitor. The resulting light scattering, refractive index and UV traces were processed in ASTRA 6 (Wyatt Technologies).

Dynamic light scattering. Samples were prepared at $1 \mathrm{mg} / \mathrm{mL}$ in $50 \mathrm{mM}$ Tris- $\mathrm{HCl}$, $150 \mathrm{mM} \mathrm{NaCl} \mathrm{pH} 8.0$ and centrifuged for $30 \mathrm{~min}$ at $16,900 \times g$ at $4{ }^{\circ} \mathrm{C}$ to remove any aggregates. $20 \mu \mathrm{L}$ of each sample was loaded into a reusable quartz cuvette and measurements were taken at $20^{\circ} \mathrm{C}$ using an Omnisizer (Viscotek) with 10 scans of $10 \mathrm{~s}$ each. Data were analyzed using OmniSIZE 3.0 and the intensity distribution from the scans were plotted in Excel.

Fluorescence assay. A concentration gradient of SpyTag-mClover3 in PBS, purified by either Spy\&Go or Ni-NTA, was prepared in triplicate from $15 \mu \mathrm{M}$ to $0.47 \mu \mathrm{M}$ in a black, flat-bottom half-area 96 -well plate (Corning). The protein was excited at $\lambda_{\mathrm{ex}}=482 \pm 16 \mathrm{~nm}$ and fluorescence intensity was detected at $\lambda_{\mathrm{em}}=530 \pm$ $40 \mathrm{~nm}$, at 40 flashes per well using a CLARIOstar plate reader (BMG Labtech) at $30{ }^{\circ} \mathrm{C}$. The fluorescence intensity was plotted using Microsoft Excel.

Cell killing assay. MDA-MB-231 cells from American Type Culture Collection were grown at $37^{\circ} \mathrm{C}$ with $5 \% \mathrm{CO}_{2}$ in Dulbecco's Modified Eagle Medium (DMEM) (Life Technologies) containing 10\% (v/v) Fetal Bovine Serum (Sigma-Aldrich) and $50 \mathrm{U} / \mathrm{mL}$ penicillin and $50 \mu \mathrm{g} / \mathrm{mL}$ streptomycin (Sigma-Aldrich). Cells were passaged upon $70-80 \%$ confluency and for $<3$ months in total. MDA-MB-231 cells were seeded into a 96-well plate at 40,000 cells per well in $100 \mu \mathrm{L}$ DMEM containing $50 \mathrm{U} / \mathrm{mL}$ penicillin and $50 \mu \mathrm{g} / \mathrm{mL}$ streptomycin and $1 \%(\mathrm{v} / \mathrm{v})$ FBS and incubated at $37^{\circ} \mathrm{C}$ with $5 \% \mathrm{CO}_{2}$ for $16 \mathrm{~h}$. Each SpyCatcher002-oligomer:aDR5SpyTag was prepared at $100 \mathrm{nM}$ monomeric concentration and serial dilutions thereof, in DMEM with antibiotics and 1\% (v/v) FBS as above. For a negative control, SpyTag-MBP (at $100 \mathrm{nM}$ and serial dilutions) was added to cells. Cells were washed with sterilized PBS twice before addition of the conjugates. The cells were incubated with the protein samples at $37^{\circ} \mathrm{C}$ with $5 \% \mathrm{CO}_{2}$ for $24 \mathrm{~h}$. Cell viability was tested by addition of $40 \mu \mathrm{L} 0.15 \mathrm{mg} / \mathrm{mL}$ Resazurin (Alamar Blue) (Sigma-Aldrich) in PBS at $37^{\circ} \mathrm{C}$ with $5 \% \mathrm{CO}_{2}$ for $4 \mathrm{~h}$ and by measuring fluorescence $\left(\lambda_{\text {ex }} 544 \mathrm{~nm}, \lambda_{\text {em }} 590 \mathrm{~nm}\right)$ using a SpectraMax3 plate reader with SoftMax Pro 5.4 software (Molecular Devices). The percentage of viable cells was calculated as $100 \times$ (signal of treated cells - signal without cells)/(signal untreated cells-signal without cells). The signal without cells was taken as the resazurin fluorescence in the absence of cells, whereas the signal of untreated cells came from the fluorescence of resazurin with cells that were incubated with DMEM with antibiotics and $1 \%(\mathrm{v} / \mathrm{v})$ FBS.

Graphics and sequence analysis. Structures are shown from SpyTag/SpyCatcher (PDB ID 4MLI $^{76}$, oDi (PDB ID: 4DZM) ${ }^{46}$, oTri (PDB ID: 4DZL) ${ }^{46}$, oTet (PDB ID: 1USE) ${ }^{49}$, oPent (PDB ID: 1VDF) ${ }^{50}$, oHex (PDB ID: 4PN9 $)^{47}$, oHept (2YF2 $)^{51}$ CC-Tet (3R4A) ${ }^{46}$, CC-Hept (4PNA) ${ }^{47}$, or PvuII (3KSK). PyMOL 2.0 was used to visualize the structure of proteins based on PDB IDs. Amino acid sequence alignment was done with Clustal Omega.

Software. Microsoft Excel was used to plot DLS and fluorescence graphs. GraphPad Prism v7.0 was used to plot the SEC-MALS graph. OriginPro 2015 was used to plot the cell killing assay and mass spectrometry graphs. MicroCal PEAQITC Analysis Software version 1.1.0.1262 was used to plot ITC graphs.

Reporting summary. Further information on experimental design is available in the Nature Research Reporting Summary linked to this article.

\section{Data availability}

Amino acid sequences of SpyDock and SpyCatcher002-oligomers are available in the Supplementary Information. Sequences of other constructs are available in GenBank as described above under "Plasmids and cloning". Plasmids encoding the SpyDock and SpyCatcher002-oligomers were deposited in the Addgene repository (https://www. addgene.org/Mark_Howarth/). The source data for Fig. 2a, b, d, 3, 4, 5, 6b, c, 7b-d, and Supplementary Figs. 1, 3, 4, 5, 6, and 8b, c are provided as a Source Data File. Further information and request for resources and reagents should be directed to and will be fulfilled by the Lead Contact, Mark Howarth (mark.howarth@bioch.ox.ac.uk).

Received: 14 December 2018 Accepted: 22 March 2019 Published online: 15 April 2019

\section{References}

1. Kimple, M. E. \& Sondek, J. Overview of affinity tags for protein purification. Curr. Protoc. Protein Sci. 73, 9.9.1-9.9.19 (2004)

2. Roque, A. C. A. \& Lowe, C. R. Affinity chromatography: history, perspectives, limitations and prospects. Methods Mol. Biol. 421, 1-21 (2008).

3. Niedzialkowska, E. et al. Protein purification and crystallization artifacts: the tale usually not told. Protein Sci. 25, 720-733 (2016).

4. Zhao, X., Li, G. \& Liang, S. Several affinity tags commonly used in chromatographic purification. J. Anal. Methods Chem. 2013, 581093 (2013).

5. Jin, J. et al. Accelerating the clinical development of protein-based vaccines for malaria by efficient purification using a four amino acid C-terminal ' $\mathrm{C}$-tag'. Int. J. Parasitol. 47, 435-446 (2017).

6. Waugh, D. S. An overview of enzymatic reagents for the removal of affinity tags. Protein Expr. Purif. 80, 283-293 (2011).

7. Waugh, D. S. Making the most of affinity tags. Trends Biotechnol. 23, 316-320 (2005).

8. De Genst, E. J. et al. Structure and properties of a complex of $\alpha$-synuclein and a single-domain camelid antibody. J. Mol. Biol. 402, 326-343 (2010).

9. Braun, M. B. et al. Peptides in headlock - a novel high-affinity and versatile peptide-binding nanobody for proteomics and microscopy. Sci. Rep. 6, 19211 (2016)

10. Vassylyeva, M. N. et al. Efficient, ultra-high-affinity chromatography in a one-step purification of complex proteins. Proc. Natl Acad. Sci. USA 114, E5138-E5147 (2017).

11. Costa, S., Almeida, A., Castro, A. \& Domingues, L. Fusion tags for protein solubility, purification, and immunogenicity in Escherichia coli: the novel Fh8 system. Front. Microbiol. 5, 63 (2014).

12. Woestenenk, E. A., Hammarström, M., Van Den Berg, S., Härd, T. \& Berglund, $\mathrm{H}$. His tag effect on solubility of human proteins produced in Escherichia coli: a comparison between four expression vectors. J. Struct. Funct. Genomics 5, 217-229 (2004).

13. Wu, J. \& Filutowicz, M. Hexahistidine (His6)-tag dependent protein dimerization: a cautionary tale. Acta Biochim. Pol. 46, 591-599 (1999).

14. Klose, J. et al. Hexa-histidin tag position influences disulfide structure but not binding behavior of in vitro folded N-terminal domain of rat corticotropinreleasing factor receptor type 2a. Protein Sci. 13, 2470-2475 (2004).

15. Sabaty, M. et al. Detrimental effect of the 6 His C-terminal tag on YedY enzymatic activity and influence of the TAT signal sequence on YedY synthesis. BMC Biochem. 14, 28 (2013).

16. Majorek, K. A., Kuhn, M. L., Chruszcz, M., Anderson, W. F. \& Minor, W. Double trouble - buffer selection and his-tag presence may be responsible for nonreproducibility of biomedical experiments. Protein Sci. 23, 1359-1368 (2014). 
17. Zhao, D. \& Huang, Z. Effect of his-tag on expression, purification, and structure of zinc finger protein, ZNF191(243-368). Bioinorg. Chem. Appl. 2016, 1-6 (2016)

18. Chant, A., Kraemer-Pecore, C. M., Watkin, R. \& Kneale, G. G. Attachment of a histidine tag to the minimal zinc finger protein of the Aspergillus nidulans gene regulatory protein AreA causes a conformational change at the DNAbinding site. Protein Expr. Purif. 39, 152-159 (2005).

19. Unzueta, U. et al. Non-amyloidogenic peptide tags for the regulatable self-assembling of protein-only nanoparticles. Biomaterials 33, 8714-8722 (2012).

20. Haglin, E. R., Briegel, A. \& Thompson, L. K. Hijacking His-Tags to make functional multi-protein complexes. Biophys. J. 112, 360a (2017).

21. Zakeri, B. et al. Peptide tag forming a rapid covalent bond to a protein through engineering a bacterial adhesin. Proc. Natl Acad. Sci. USA 109, E690-E697 (2012).

22. Sutherland, A. R., Alam, M. K. \& Geyer, C. R. Post-translation assembly of protein parts into complex devices using SpyTag/SpyCatcher protein ligase. Chembiochem 20, 319-328 (2019).

23. Keeble, A. H. et al. Evolving accelerated amidation by SpyTag/SpyCatcher to analyze membrane dynamics. Angew. Chem. Int. Ed. 56, 16521-16525 (2017).

24. Brune, K. D. et al. Plug-and-Display: decoration of Virus-Like Particles via isopeptide bonds for modular immunization. Sci. Rep. 6, 19234 (2016)

25. Brune, K. D. et al. Dual Plug-and-Display synthetic assembly using orthogonal reactive proteins for twin antigen immunization. Bioconjug. Chem. 28, 1544-1551 (2017).

26. Bruun, T. U. J., Andersson, A.-M. C., Draper, S. J. \& Howarth, M. Engineering a rugged nanoscaffold to enhance plug-and-display vaccination. ACS Nano 12 , 8855-8866 (2018).

27. Fairhead, M. et al. SpyAvidin hubs enable precise and ultrastable orthogonal nanoassembly. J. Am. Chem. Soc. 136, 12355-12363 (2014).

28. Moon, H., Bae, Y., Kim, H. \& Kang, S. Plug-and-playable fluorescent cell imaging modular toolkits using the bacterial superglue, SpyTag/SpyCatcher. Chem. Commun. 52, 14051-14054 (2016).

29. Sun, F., Zhang, W.-B., Mahdavi, A., Arnold, F. H. \& Tirrell, D. A. Synthesis of bioactive protein hydrogels by genetically encoded SpyTag-SpyCatcher chemistry. Proc. Natl Acad. Sci. USA 111, 11269-11274 (2014).

30. Wieduwild, R. \& Howarth, M. Assembling and decorating hyaluronan hydrogels with twin protein superglues to mimic cell-cell interactions. Biomaterials 180, 253-264 (2018).

31. Nguyen, P. Q., Botyanszki, Z., Tay, P. K. R. \& Joshi, N. S. Programmable biofilm-based materials from engineered curli nanofibres. Nat. Commun. 5 , 4945 (2014).

32. Peschke, T. et al. Self-assembling all-enzyme hydrogels for flow biocatalysis. Angew. Chem. Int. Ed. 57, 17028-17032 (2018).

33. Reddington, S. C. \& Howarth, M. Secrets of a covalent interaction for biomaterials and biotechnology: SpyTag and SpyCatcher. Curr. Opin. Chem. Biol. 29, 94-99 (2015).

34. Pessino, V., Citron, Y. R., Feng, S. \& Huang, B. Covalent protein labeling by SpyTag-SpyCatcher in fixed cells for super-resolution microscopy. Chembiochem 18, 1492-1495 (2017).

35. Dovala, D., Sawyer, W. S., Rath, C. M. \& Metzger, L. E. Rapid analysis of protein expression and solubility with the SpyTag-SpyCatcher system. Protein Expr. Purif. 117, 44-51 (2016).

36. Buldun, C. M., Jean, J. X., Bedford, M. R. \& Howarth, M. SnoopLigase catalyzes peptide-peptide locking and enables solid-phase conjugate isolation. J. Am. Chem. Soc. 140, 3008-3018 (2018).

37. Brune, K. D. \& Howarth, M. New routes and opportunities for modular construction of particulate vaccines: stick, click, and glue. Front. Immunol. 9, 1432 (2018).

38. Keeble, A. H. \& Howarth, M. Insider information on successful covalent protein coupling with help from SpyBank. Methods Enzymol. 617, 443-461 (2019).

39. Bass, R. B., Miller, A. S., Gloor, S. L. \& Falke, J. J. The PICM chemical scanning method for identifying domain-domain and protein-protein interfaces: applications to the core signaling complex of E. coli chemotaxis. Methods Enzymol. 423, 3-24 (2007).

40. Schmidt, T. G. M. et al. Development of the Twin-Strep-tag ${ }^{\circledR}$ and its application for purification of recombinant proteins from cell culture supernatants. Protein Expr. Purif. 92, 54-61 (2013).

41. Seiradake, E., Zhao, Y., Lu, W., Aricescu, A. R. \& Jones, E. Y. Production of cell surface and secreted glycoproteins in mammalian cells. Methods Mol. Biol.1261, 115-127 (2015)

42. Jain, J., Veggiani, G. \& Howarth, M. Cholesterol loading and ultrastable protein interactions determine the level of tumor marker required for optimal isolation of cancer cells. Cancer Res. 73, 2310-2321 (2013).

43. Huang, L. et al. Functions of EpCAM in physiological processes and diseases (Review). Int. J. Mol. Med. 42, 1771-1785 (2018).
44. Dreyer, A. M. et al. Passive immunoprotection of plasmodium falciparum infected mice designates the CyRPA as candidate malaria vaccine antigen. J. Immunol. 188, 6225-6237 (2012).

45. Zhang, W. B., Sun, F., Tirrell, D. A. \& Arnold, F. H. Controlling macromolecular topology with genetically encoded SpyTag-SpyCatcher chemistry. J. Am. Chem. Soc. 135, 13988-13997 (2013).

46. Fletcher, J. M. et al. A basis set of de novo coiled-Coil peptide oligomers for rational protein design and synthetic biology. ACS Synth. Biol. 1, 240-250 (2012).

47. Thomson, A. R. et al. Computational design of water-soluble $\alpha$-helical barrels. Science 346, 485-488 (2014)

48. Thomas, F., Boyle, A. L., Burton, A. J. \& Woolfson, D. N. A set of de novo designed parallel heterodimeric coiled coils with quantified dissociation constants in the micromolar to sub-nanomolar regime. J. Am. Chem. Soc. 135, 5161-5166 (2013)

49. Karin, K. et al. The VASP tetramerization domain is a right-handed coiled coil based on a 15-residue repeat. Proc. Natl Acad. Sci. USA 101, 17027-17032 (2004).

50. Malashkevich, V. N., Kammerer, R. A., Efimov, V. P., Schulthess, T. \& Engel, J. The crystal structure of a five-stranded coiled coil in COMP: A prototype ion channel? Science 274, 761-765 (1996).

51. Ogun, S. A., Dumon-Seignovert, L., Marchand, J. B., Holder, A. A. \& Hill, F. The oligomerization domain of C4-binding protein (C4bp) acts as an adjuvant, and the fusion protein comprised of the 19-kilodalton merozoite surface protein 1 fused with the murine C4bp domain protects mice against malaria. Infect. Immunol. 76, 3817-3823 (2008).

52. Bertsch, U., Röder, C., Kalthoff, H. \& Trauzold, A. Compartmentalization of TNF-related apoptosis-inducing ligand (TRAIL) death receptor functions: emerging role of nuclear TRAIL-R2. Cell Death Dis. 5, e1390-e1390 (2014).

53. Dubuisson, A. \& Micheau, O. Antibodies and derivatives targeting DR4 and DR5 for cancer therapy. Antibodies 6, 16 (2017).

54. Veggiani, G. et al. Programmable polyproteams built using twin peptide superglues. Proc. Natl Acad. Sci. USA 113, 1202-1207 (2016).

55. Huet, $\mathrm{H}$. A. et al. Multivalent nanobodies targeting death receptor 5 elicit superior tumor cell killing through efficient caspase induction. MAbs 6, 1560-1570 (2014)

56. Hutt, M. et al. Superior properties of Fc-comprising scTRAIL fusion proteins. Mol. Cancer Ther. 16, 2792-2802 (2017).

57. Swers, J. S. et al. Multivalent scaffold proteins as superagonists of TRAIL receptor 2-induced apoptosis. Mol. Cancer Ther. 12, 1235-1244 (2013).

58. Graves, J. D. et al. Apo2L/TRAIL and the death receptor 5 agonist antibody AMG 655 cooperate to promote receptor clustering and antitumor activity. Cancer Cell 26, 177-189 (2014).

59. Gieffers, C. et al. APG350 induces superior clustering of TRAIL receptors and shows therapeutic antitumor efficacy independent of cross-linking via Fc receptors. Mol. Cancer Ther. 12, 2735-2747 (2013).

60. Bruenker, P. et al. RG7386, a novel tetravalent FAP-DR5 antibody, effectively triggers FAP-dependent, avidity-driven DR5 hyperclustering and tumor cell apoptosis. Mol. Cancer Ther. 15, 946-957 (2016).

61. Hagen, A., Sutter, M., Sloan, N. \& Kerfeld, C. A. Programmed loading and rapid purification of engineered bacterial microcompartment shells. Nat. Commun. 9, 2881 (2018).

62. Way, J. C., Collins, J. J., Keasling, J. D. \& Silver, P. A. Integrating biological redesign: where synthetic biology came from and where it needs to go. Cell 157, 151-161 (2014).

63. Ross, J. F. et al. Decorating self-assembled peptide cages with proteins. ACS Nano 11, 7901-7914 (2017).

64. Zhu, X. et al. COMBODY: one-domain antibody multimer with improved avidity. Immunol. Cell Biol. 88, 667-675 (2010).

65. Müller, K. M., Arndt, K. M. \& Alber, T. Protein fusions to coiled-coil domains Methods Enzymol. 328, 261-282 (2000).

66. He, Y. G. et al. A novel C3d-containing oligomeric vaccine provides insight into the viability of testing human $\mathrm{C} 3 \mathrm{~d}$-based vaccines in mice. Immunobiology 223, 125-134 (2018).

67. Voulgaraki, D. et al. Multivalent recombinant proteins for probing functions of leucocyte surface proteins such as the CD200 receptor. Immunology 115 , 337-346 (2005).

68. Arndt, K. M., Müller, K. M. \& Plückthun, A. Helix-stabilized fv (hsfv) antibody fragments: substituting the constant domains of a fab fragment for a heterodimeric coiled-coil domain. J. Mol. Biol. 312, 221-228 (2001).

69. Müller, K. M., Arndt, K. M. \& Alber, T. Protein fusions to coiled-coil domains Methods Enzymol. 328, 261-282 (2000).

70. Wang, W., He, W., Wang, L., Zhang, G. \& Gao, B. Pentamerisation of a scFv directed against TRAIL receptor 2 increases its antitumour efficacy. Immunol. Cell Biol. 91, 360-367 (2013). 
71. Miller, H., Zhou, Z., Shepherd, J., Wollman, A. J. M. \& Leake, M. C. Singlemolecule techniques in biophysics: a review of the progress in methods and applications. Reports Prog. Phys. 81, 024601 (2018).

72. Günther, J. P., Börsch, M. \& Fischer, P. Diffusion measurements of swimming enzymes with fluorescence correlation spectroscopy. Acc. Chem. Res. 51, 1911-1920 (2018).

73. Dubacheva, G. V., Curk, T., Auzély-Velty, R., Frenkel, D. \& Richter, R. P. Designing multivalent probes for tunable superselective targeting. Proc. Natl Acad. Sci. USA 112, 5579-5584 (2015).

74. Kiessling, L. L., Gestwicki, J. E. \& Strong, L. E. Synthetic multivalent ligands as probes of signal transduction. Angew. Chem. Int. Ed. 45, 2348-2368 (2006)

75. Bajar, B. T. et al. Improving brightness and photostability of green and red fluorescent proteins for live cell imaging and FRET reporting. Sci. Rep. 6, 20889 (2016).

76. Li, L., Fierer, J. O., Rapoport, T. A. \& Howarth, M. Structural analysis and optimization of the covalent association between SpyCatcher and a peptide tag. J. Mol. Biol. 426, 309-317 (2014).

77. Guruprasad, K. \& Rajkumar, S. Beta-and gamma-turns in proteins revisited: a new set of amino acid turn-type dependent positional preferences and potentials. J. Biosci. 25, 143-156 (2000).

78. Fu, H., Grimsley, G. R., Razvi, A., Scholtz, J. M. \& Pace, C. N. Increasing protein stability by improving Beta-turns. Proteins Struct. Funct. Bioinform. 77, 491-498 (2009).

79. Yu, H., Yan, Y., Zhang, C. \& Dalby, P. A. Two strategies to engineer flexible loops for improved enzyme thermostability. Sci. Rep. 7, 41212 (2017).

80. Aon, J. C. et al. Suppressing posttranslational gluconoylation of heterologous proteins by metabolic engineering of Escherichia coli. Appl. Environ. Microbiol. 74, 950-958 (2008).

\section{Acknowledgements}

Funding was provided by Yayasan Khazanah, Oxford Centre for Islamic Studies, St. John's College Oxford (I.N.A.K.A.), the European Research Council (ERC-2013-CoG 615945-PeptidePadlock) (A.B., A.H.K., and M.H.), and the Biotechnology and Biological Sciences Research Council (BBSRC Research Experience Placements) (G.I.N.). We thank Dr. David Staunton of the University of Oxford Department of Biochemistry Biophysical Suite for assistance. We acknowledge Dr. Anthony Tumber of the University of Oxford Department of Chemistry for assistance with MS, supported by the BBSRC (grant BB/ R000344/1). We thank Dr. James F. Ross (Howarth laboratory), Dr. Anne-Marie C. Andersson (Howarth laboratory), and Dr. Karthik Rajasekar (David Sherratt laboratory) for advice.

\section{Author contributions}

I.N.A.K.A. performed all experiments except for cellular analysis and ITC. A.B. performed cellular analysis. A.H.K. performed ITC. A.H.K., A.C., and G.I.N. performed early optimization of SpyDock reactivity. I.N.A.K.A. and M.H. designed the project and wrote the manuscript. All authors approved the manuscript.

\section{Additional information}

Supplementary Information accompanies this paper at https://doi.org/10.1038/s41467019-09678-w.

Competing interests: M.H., A.H.K., and A.C. are authors on a patent application by the University of Oxford covering sequences for enhanced isopeptide bond formation (UK Intellectual Property Office 1706430.4). M.H. is an author on a granted patent covering peptide tags forming spontaneous isopeptide bonds (EP2534484) and a SpyBiotech co-founder, shareholder, and consultant. M.H. and I.N.A.K.A. are authors on a patent application by the University of Oxford covering Spy\&Go (UK Intellectual Property Office 1819850.7). The remaining authors declare no competing interests.

Reprints and permission information is available online at http://npg.nature.com/ reprintsandpermissions/

Journal peer review information: Nature Communications thanks Sebyung Kang and the other anonymous reviewer(s) for their contribution to the peer review of this work.

Publisher's note: Springer Nature remains neutral with regard to jurisdictional claims in published maps and institutional affiliations.

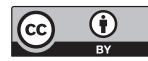

Open Access This article is licensed under a Creative Commons Attribution 4.0 International License, which permits use, sharing, adaptation, distribution and reproduction in any medium or format, as long as you give appropriate credit to the original author(s) and the source, provide a link to the Creative Commons license, and indicate if changes were made. The images or other third party material in this article are included in the article's Creative Commons license, unless indicated otherwise in a credit line to the material. If material is not included in the article's Creative Commons license and your intended use is not permitted by statutory regulation or exceeds the permitted use, you will need to obtain permission directly from the copyright holder. To view a copy of this license, visit http://creativecommons.org/ licenses/by/4.0/.

(c) The Author(s) 2019 